\title{
Distinct Correlation Structure Supporting a Rate-Code for Sound Localization in the Owl's Auditory Forebrain
}

\author{
(D) Michael V. Beckert, ${ }^{\circledR}$ Rodrigo Pavão, and José L. Peña
}

DOI:http://dx.doi.org/10.1523/ENEURO.0144-17.2017

Dominick P. Purpura Department of Neuroscience, Albert Einstein College of Medicine, Bronx, NY 10461

\begin{abstract}
While a topographic map of auditory space exists in the vertebrate midbrain, it is absent in the forebrain. Yet, both brain regions are implicated in sound localization. The heterogeneous spatial tuning of adjacent sites in the forebrain compared to the midbrain reflects different underlying circuitries, which is expected to affect the correlation structure, i.e., signal (similarity of tuning) and noise (trial-by-trial variability) correlations. Recent studies have drawn attention to the impact of response correlations on the information readout from a neural population. We thus analyzed the correlation structure in midbrain and forebrain regions of the barn owl's auditory system. Tetrodes were used to record in the midbrain and two forebrain regions, Field $L$ and the downstream auditory arcopallium (AAr), in anesthetized owls. Nearby neurons in the midbrain showed high signal and noise correlations $\left(R_{N C} s\right)$, consistent with shared inputs. As previously reported, Field $L$ was arranged in random clusters of similarly tuned neurons. Interestingly, AAr neurons displayed homogeneous monotonic azimuth tuning, while response variability of nearby neurons was significantly less correlated than the midbrain. Using a decoding approach, we demonstrate that low $\mathrm{R}_{N C}$ in $\mathrm{AAr}$ restricts the potentially detrimental effect it can have on information, assuming a rate code proposed for mammalian sound localization. This study harnesses the power of correlation structure analysis to investigate the coding of auditory space. Our findings demonstrate distinct correlation structures in the auditory midbrain and forebrain, which would be beneficial for a rate-code framework for sound localization in the nontopographic forebrain representation of auditory space.
\end{abstract}

\section{Significance Statement}

Despite their established involvement in sound localization, our understanding of how the midbrain and forebrain encode sound location is limited. An outstanding difference between these regions is the lack of obvious topographic representations of auditory space in the forebrain. To shed light on the circuit function, we examined the tuning and correlation structure in responses of nearby neurons in the midbrain and forebrain. Interestingly, a different correlation structure emerged in the forebrain: uniform tuning shape and uncorrelated response variability. This finding highlights differences between the midbrain and forebrain representation of auditory space and provides evidence supporting a rate code for sound location in the forebrain.

\section{Introduction}

The barn owl is a nocturnal predator capable of hunting in darkness using auditory cues (Payne, 1971). Owls can use interaural time difference (ITD; Moiseff and Konishi,

Received April 26, 2017; accepted June 7, 2017; First published June 26, 2017.

The authors declare no competing financial interests.
1981) across their entire hearing range, $100-10,000 \mathrm{~Hz}$ (Köppl, 1997), to calculate the horizontal position (azimuth) of sound sources with high acuity (Knudsen et al., 1979; Moiseff, 1989; Poganiatz et al., 2001). Downstream 


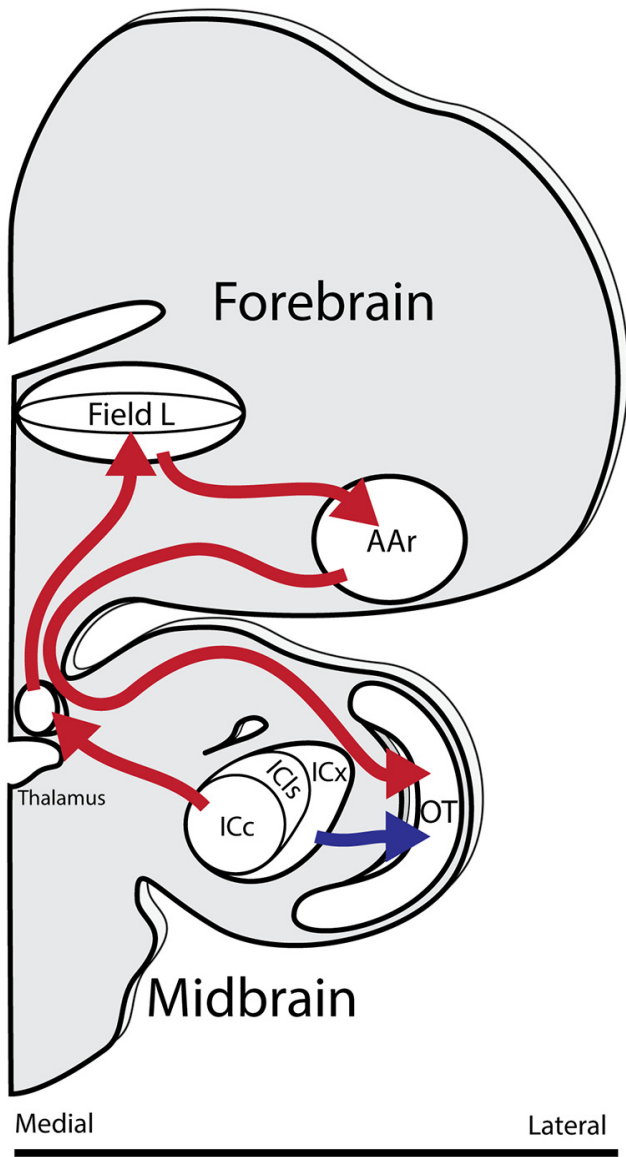

Figure 1. Schematic of tectal (blue) and forebrain (red) auditory pathways of the owl's brain. The auditory midbrain consists of subdivisions of the inferior colliculus: the central core (ICc), lateral shell (ICls), and external nucleus (ICX). The map of auditory space first emerges in ICx. ICx projects to the OT, analog to the superior colliculus. The forebrain pathway originates in projections from the inferior colliculus to the thalamus. The auditory forebrain structure Field L, analog to primary auditory cortex, displays a clustered nontopographic tuning to binaural cues. Field $L$ projects directly to the $A A r$, analog to the auditory portion of the frontal eye fields. AAr sends projections back onto OT. For clarity, some connections are omitted.

from the brainstem, the owl's auditory system separates into the tectal and forebrain pathways (Fig. 1). Headorienting behavior to sound is maintained or recovers

This work was supported by the National Institute of Health Grant DC007690.

Acknowledgements: We thank Dr. Brian Fischer and Dr. Ruben Coen-Cagli for their invaluable feedback on this work and discussions regarding interpretations, as well as Dr. Gervasio Batista for comments on early versions of this manuscript. We also thank Dr. Adam Kohn for his integral guidance for the correlation analysis.

Correspondence should be addressed to José L. Peña, 1410 Pelham Parkway South, Room K529, Albert Einstein College of Medicine, Bronx, NY 10461. E-mail: jose.pena@einstein.yu.edu.

DOl:http://dx.doi.org/10.1523/ENEURO.0144-17.2017

Copyright () 2017 Beckert et al.

This is an open-access article distributed under the terms of the Creative Commons Attribution 4.0 International license, which permits unrestricted use, distribution and reproduction in any medium provided that the original work is properly attributed. after lesion of the forebrain or tectal pathways, respectively, but is lost when both are ablated, suggesting one pathway may compensate for the loss of the other and either is sufficient to support the function (Knudsen et al., 1993; Wagner, 1993). Yet, the spatial tuning of neurons is arranged differently in these pathways. The tectal pathway displays a map of auditory space in the external nucleus of the inferior colliculus (Knudsen and Konishi, 1978) and the optic tectum (OT; Knudsen and Knudsen, 1983), analogous to the superior colliculus (Knudsen, 1982). In contrast, the forebrain regions the auditory arcopallium (AAr), analogous to the auditory portion of cortical frontal eye fields (Knudsen et al., 1995), and its primary input region, Field L, analogous to primary auditory cortex (Cohen et al., 1998), contain random clusters of similarly tuned neurons (Cohen and Knudsen, 1995, 1998). This nontopographic organization is also observed in the mammalian auditory cortex, e.g., nonhuman primates (Benson et al., 1981), cats (Eisenman, 1974; Middlebrooks and Pettigrew, 1981), and bats (Razak et al., 2015). The qualitatively distinct organization of midbrain and forebrain reflects differences in network architecture and suggests that coding schemes across brain regions may also differ.

An essential difference between topographic and nontopographic representations is the relationship between the tuning of neighboring cells. Specifically, the tuning of nearby cells in a topographic representation is similar and predictable. From a connectivity viewpoint, similarity of tuning in nearby cells reflects shared inputs. The amount of shared inputs by nearby cells also determines their trial-bytrial response variability (Shadlen and Newsome, 1998). Tuning similarity and trial-by-trial variability are known as signal (Gawne and Richmond, 1993) and noise (van Kan et al., 1985) correlation, respectively, and jointly referred to as the correlation structure (Zohary et al., 1994; Bair et al., 2001; Seriès et al., 2004; Averbeck et al., 2006). An additional indicator of shared inputs is spike synchrony (Miller et al., 2014; Atencio et al., 2016; Sabri et al., 2016; Schwab et al., 2017; Yaeger and Trussell, 2016).

The impact of correlations depends on many factors: coding scheme (Paradiso, 1988; Seung and Sompolinsky, 1993; Butts and Goldman, 2006; Latham and Roudi, 2013), network architecture, and upstream computations (Kohn et al., 2016). The extensive description of sound localization mechanisms in the owl's brain (Takahashi, 2010; Konishi, 2012; Wagner et al., 2013) makes this system well suited for insightful interpretations. Specifically, we considered the two-channel theory of how ITD is encoded for sound localization. This theory postulates that differential activity in two hemispheric populations can explain lateralization of sound sources (Békésy, 1930; van Bergeijk, 1962). There is growing evidence that this coding scheme is implemented in rodents (McAlpine et al., 2001; Grothe et al., 2010) and humans (Briley et al., 2013; Derey et al., 2016; McLaughlin et al., 2016). The competing hemispheric channels would result from populations of neurons with mirrored monotonic tuning. Because noise correlation $\left(R_{N C}\right)$ affects information drawn from the firing rate of homogeneously tuned populations 
(Ecker et al., 2011; Zohar et al., 2013), it could impact information under this coding scheme.

Correlation analysis requires simultaneous recording of multiple neurons, a task which has been notoriously difficult in the auditory system (Syka et al., 1981; Gray et al., 1995; Richardson et al., 2013). To this end, we conducted tetrode recordings for the first time in the owl's auditory regions OT, Field L, and AAr. Nearby OT cells were similarly tuned and their responses covaried, consistent with a topographic representation. On the other hand, Field $L$ showed clusters of similarly tuned neurons, consistent with previous reports (Cohen and Knudsen, 1998). Intriguingly, cells in AAr displayed uniform tuning across the population and strikingly low $\mathrm{R}_{N C}$ and synchrony of nearby cells. Furthermore, we show AAr's correlation structure is beneficial under a rate-code framework. These findings demonstrate that the difference between the midbrain and forebrain goes beyond large scale topography, displaying distinct correlation structures that may be important for how sound location is encoded in the forebrain.

\section{Materials and Methods}

\section{Subjects and surgery}

Adult American barn owls (Tyto furcata) of both sexes (four male and one female) were implanted with custom built stainless steel headplates (Einstein Engineering Department). Dental acrylic was used to form a molded well aimed over OT, Field L, and AAr for repeated recordings.

Owls were food deprived $12 \mathrm{~h}$ preceding each recording session. During recording sessions, owls were anesthetized with intramuscular injections of ketamine (Ketaset; $20 \mathrm{mg} /$ $\mathrm{kg}$ ) and xylazine (Anased; $2 \mathrm{mg} / \mathrm{kg}$ ), along with prophylactic antibiotics (ampicillin; 20 mg/kg, i.m.) and lactated Ringer's solution (10 ml, s.c.). Anesthesia level was assessed by pedal and eyelid reflex. Subsequent half doses of ketamine and xylazine were administered throughout the recording session as needed, to maintain a proper anesthesia level. Body temperature was maintained with a heating pad.

At the end of each session the craniotomy and well in the head cap was sealed with a silicone compound (Quick-Pro, Warner Tech-Care). An analgesic was administered intramuscularly ( $3 \mathrm{mg} / \mathrm{kg}$; Rimadyl) to prevent inflammation and pain. Owls were allowed to recover overnight in a small crate. They were returned to the home aviary when all physical impairment signs were absent. Owls recovered for $>10 \mathrm{~d}$ before another recording session. All procedures were in compliance with guidelines set by the National Institutes of Health and Albert Einstein College of Medicine's Institute for Animal Studies.

\section{Data collection}

All recordings were performed in a double wall sound attenuated chamber (Industrial Acoustics), lined with anechoic acoustic foam (Sonex). OT, Field L, and AAr were targeted stereotaxically using known coordinates relative to the intersection of the midline and interaural line as well as by established physiologic response properties: response latency, spontaneous firing rate, and tuning to ITD, interaural level difference (ILD), and frequency (Knud- sen and Konishi, 1978; Knudsen and Knudsen, 1983; Knudsen et al., 1993, 1995; Wagner, 1993; Cohen and Knudsen, 1995, 1996, 1998; Cohen et al., 1998; Vonderschen and Wagner, 2009, 2012).

Tetrodes (Q-trodes, NeuroNexus) were advanced through small openings in the dura made with a sterile needle, using a micromanipulator (David Kopf Instruments). Tetrodes were chosen to achieve simultaneous recording of multiple nearby single units which is necessary to perform correlation analysis. Data acquisition was performed using a Plexon Omniplex system (SortClient, Plexon). We recorded sites containing at least two visually well-isolated units. After the recording, isolation was confirmed with offline sorting software (Offline Sorter, Plexon), with an average of four to five units separated per site.

Collecting the data necessary for the analysis of signal and $R_{N C} S$ and synchrony, under dichotic and free-field stimulation required long acquisition times for each recording site. Thus, often recordings were not successfully held for the amount of time necessary to obtain data for every type of analysis. The sample size of each dataset is provided in the results.

\section{Acoustic stimulation \\ Dichotic stimulation}

Dichotic (earphone) stimulation was used to identify recording sites. Acoustic stimulation was performed using previously described methods (Steinberg and Peña, 2011; Wang et al., 2012; Steinberg et al., 2013; Wang and Peña, 2013; Cazettes et al., 2014, 2016). Briefly, Tucker-Davis Technologies System 3 and custom written MatLab (Mathworks) routines were used to synthesize and deliver all acoustic stimuli. Custom-made earphones (Einstein Engineering Department) containing a speaker (Knowles, model 1914) and a microphone (Knowles, model 1319) were inserted into the owl's ear canal. The earphone microphones were then used to correct irregularities in phase and level across frequency of earphone speakers each time they were positioned in the ear canals. The tuning to ITD and ILD as well as frequency was used to identify recording sites by the response properties characteristic of OT, Field L, and AAr neurons.

After a site was confirmed with dichotic stimulation, the earphones were removed to allow for free-field stimulation.

\section{Free-field stimulation}

Free-field sound stimulation was presented through a custom built spherical array of speakers (Sennheiser, 3P127A) surrounding the stereotax (Pérez and Peña, 2006; Pérez et al., 2009; Wang et al., 2012; Wang and Peña, 2013). Speaker positions ranged from $\pm 100^{\circ}$ azimuth and $\pm 80^{\circ}$ elevation with spacing between $10^{\circ}$ and $30^{\circ}$. For combining data across hemispheres, azimuth was normalized such that positive values corresponded to contralateral space relative to the recording side. Owls were positioned to face the $0^{\circ}$ azimuth and $0^{\circ}$ elevation speaker for all recordings. Speakers were calibrated using a Brüel and Kjær microphone (model 4190). Broadband signals $(500 \mathrm{~Hz}$ to $10 \mathrm{kHz}$ ) were transformed by the calibration filter for each speaker to equalize sounds across 
the array. Stimulus duration and interstimulus intervals were the same as those used for site confirmation with dichotic stimulation (150 and $300 \mathrm{~ms}$, respectively). Speakers were activated randomly 20-40 times to measure a spatial receptive field (SpRF).

After the free-field stimulation protocol was completed, the earphones were repositioned and recalibrated, to search for subsequent recording sites.

\section{Data analysis}

\section{Tuning curves}

Action potentials occurring during the stimulus (150-ms window after stimulus onset) were binned and averaged to generate SpRFs. The mean firing rate within a window equivalent to the stimulus duration that preceded the stimulus onset was used to assess spontaneous activity. Neurons were included in the sample if they showed a significant response to sound, i.e., if the firing rate during sound stimulation was two standard deviations above the spontaneous activity, and considered tuned if the mean peak activity of the tuning curve was two standard deviations above the lowest mean response. SpRFs were transformed into azimuth tuning curves by averaging response across speakers with equivalent azimuths (Fig. $2 B$ ). Azimuth tuning curves for Field $L$ and AAr were smoothed using $30^{\circ}$ sliding windows. This method has been used to facilitate the characterization of tuning curves in Field L and AAr (Vonderschen and Wagner, 2009). The same procedure was used to generate ITD tuning curves in Field $L$ and $A A r$ to assess the similarity of shape across recording sites.

To further characterize AAr tuning, azimuth curves were subdivided into three regions: frontal $\left( \pm 40^{\circ}\right)$, contralateral $\left(+50^{\circ}\right.$ to $\left.+100^{\circ}\right)$ and ipsilateral $\left(-50^{\circ}\right.$ to $\left.-100^{\circ}\right)$ portions. The slope of the tuning curves within each of these regions was assessed by computing the mean slope of linear regressions for a sliding window of three consecutive curve data points, spanning over $30^{\circ}$ in azimuth. This method permitted a fine description of the change in slope while smoothing out noise.

\section{Correlation analysis}

Tuning similarity was assessed with the commonly used signal correlation (Bair et al., 2001; Sompolinsky et al., 2001; Kohn and Smith, 2005; Lyamzin et al., 2010; Chelaru and Dragoi, 2016). Signal correlation is the Pearson productmoment correlation coefficient $(R)$ for tuning curves of pair of neurons (Liu et al., 2013). Correlation coefficients $\left(R_{\text {sig }}\right)$ were converted using Fisher's z-transformation for statistical purposes and converted back to $R$ values for reporting (Silver and Dunlap, 1987; Kohn and Smith, 2005; Smith and Kohn, 2008). Signal correlations in pairs of simultaneously recorded neurons are referred to as correlations computed "within" recording sites. Additionally, for Field L and AAr, signal correlations were computed "across" recording sites (not simultaneously recorded) to examine the homogeneity of tuning across the population.

$\mathrm{R}_{N C}$ is the trial-by-trial response variability of pairs of neurons over repeated presentations of a frozen (identical) stimulus. This is the Pearson correlation coefficient of spike counts per trial (150 ms each trial; Bair et al., 2001;
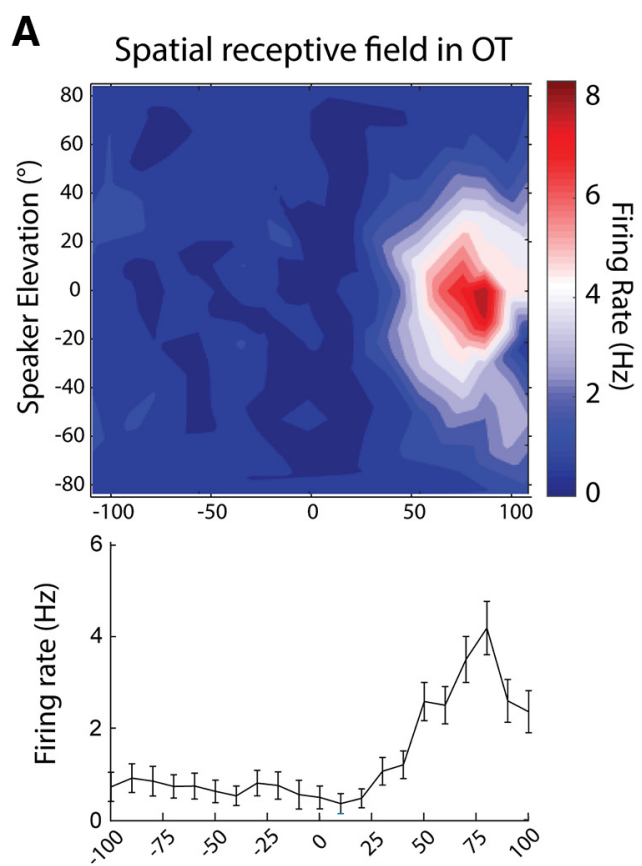

B
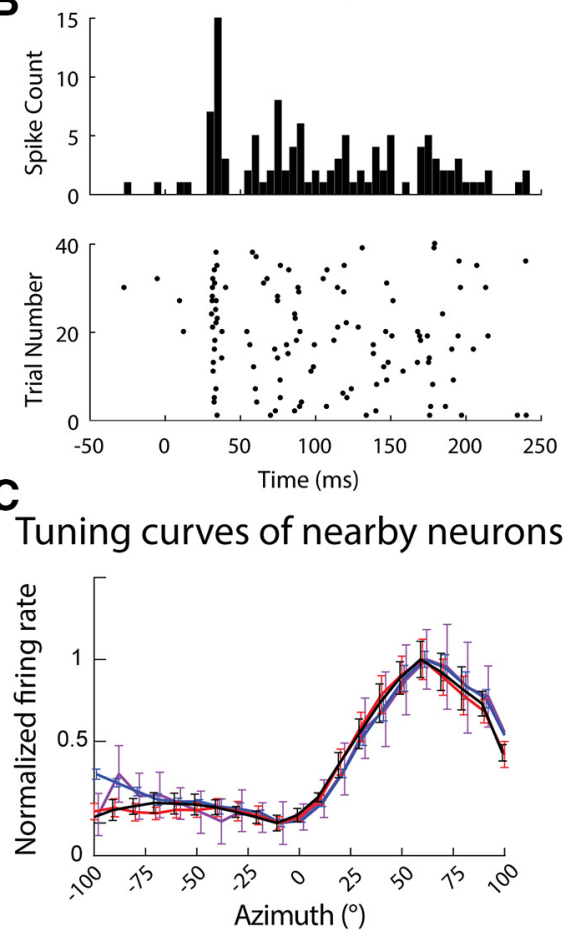

Figure 2. Azimuth tuning of nearby neurons in OT. $\boldsymbol{A}$, Spatial receptive field (SpRF) (top) and azimuth tuning curve (bottom) obtained by averaging the SpRF across elevation. B, Peristimulus time histogram (PSTH; top) and raster (bottom) for the spiking activity of the neuron in $\boldsymbol{A}$ responding to sound at the preferred direction ( $90^{\circ}$ azimuth and $0^{\circ}$ elevation). C, Example azimuth tuning curves of neurons recorded from the same site. Responses are normalized to facilitate visual comparison. Tuning curves represent mean \pm SEM, 20-40 repetitions.

Kohn and Smith, 2005; Smith and Kohn, 2008; Liu et al., 2013). The calculation of a correlation coefficient is affected by the sample size, i.e., the number of trials, used 
for each pair. Consider a model distribution of spike counts with a known correlation. As sample size increases the calculated correlation will on average approach the known value; while with few samples the variability of calculated correlations increases. Thus, a single measurement of correlation with a small sample size may not accurately represent the true correlation of a pair. However, the average of repeated measures would be closer to the actual value and could be used to better estimate the correlation (Schönbrodt and Perugini, 2013). To ensure the accurate assessment of the strength of $R_{N C} s, R_{N C}$ was calculated for each free-field speaker and then averaged. If a neuron is quiescent, this can also yield a similar effect to reducing the sample size. Therefore, only speakers that elicited a response in at least three trials were included. $\mathrm{R}_{N C}$ was converted using Fisher's z-transformation for statistics and comparisons. $\mathrm{Z}$ values were then converted back to $R$ values for reporting.

The synchrony of two simultaneously recorded neurons was computed by generating cross-correlograms (CCGs) of their spike trains (Bair et al., 2001; de la Rocha et al., 2007; Smith and Kohn, 2008). Continuous neural data were converted into binary sequences representing the presence of spikes in time (Offline Sorter, Plexon). CCGs with lags of $\pm 100 \mathrm{~ms}$ within a $1-\mathrm{ms}$ bin size were computed for either the duration of the stimulus (150 ms) or an equivalent amount of time preceding the stimulus onset, evoked and spontaneous, respectively. CCGs were then smoothed using a 5-ms sliding window and normalized by the geometric mean firing rate of the neurons and size of the analysis window (Bair et al., 2001). The magnitude of the CCG will increase with firing rate as spikes coincide due to chance alone. To correct for this, a shifted CCG was computed and smoothed. In this case the spike train of one neuron for one trial $\left(n_{i}\right)$ was compared with the spike train of the other neuron on the subsequent trial $\left(n_{i+1}\right)$. This shifted CCG was subtracted from the original CCG to compute the corrected CCG. Synchrony was then quantified by the integral of the peak of the CCG at 0-lag. The peak boundaries were selected by a half-maximum algorithm. For each pair, average synchrony values were obtained from all trials using unfrozen noise stimulation that evoked a significant response (see above, Tuning curves) during free-field and dichotic stimulation.

\section{Decoding analysis}

Azimuthal information in the firing rate of OT, Field L, and AAr neurons was assessed using linear discriminant analysis (Fisher, 1936; Quiroga et al., 2007). The decoder was trained with pairs of simultaneously recorded neurons. This allowed us to train the decoder with actual trial-by-trial neural responses and preserved the embedded correlation structure. This procedure permits a parsimonious estimate of the information contained in a neural population compared with bigger pools which include nonsimultaneously recorded neurons (Miller and Recanzone, 2009; Day and Delgutte, 2013; Goodman et al., 2013; Belliveau et al., 2014). This particular decoder (built-in MatLab function "classify," Mathworks) determines the linear boundary between measures that maxi- mally separates the responses to different classes of stimuli, in this case the firing rates of pairs of neurons that separate azimuths. This boundary depends on the signal and $\mathrm{R}_{N C} \mathrm{~s}$ for the pair (Averbeck et al., 2006). For example, let us consider two neurons responding to two sounds from different speakers in azimuth 1 and 2 . If the tunings of these neurons are positively correlated, such that both respond strongly to 1 and weakly to 2 and the variability of their responses is independent (low $R_{N C} s$ ), then the optimal classifier would form a line orthogonal to the identity line (i.e., where the responses of the two cells are perfectly matched) lying between the responses of these neurons to each stimulus trial plotted against one another. Alternatively, if the tunings for the neurons are inversely correlated, then the discrimination line that maximally separates responses would be the identity line.

The decoder was trained with neural responses to repeated trials across all speaker positions labeled by their azimuths, to determine the optimal discrimination lines that correctly classified these categories. To exclude noninformative portions of the tuning curves from the analysis of decoding performance, the 21 azimuth categories $\left( \pm 100^{\circ}\right.$ in steps of $\left.10^{\circ}\right)$ were down-sampled to 7 by merging three consecutive azimuths. This bin size preserved the shape of each tuning curve while eliminating redundancy. Signal correlations computed for original and down-sampled curves were strongly correlated for all regions [correlation coefficients $(R)$ : OT $=0.94$, Field $\mathrm{L}=$ 0.91 , AAr $=0.91 ; p<0.0001$ for all]. The decoder was cross-validated by the "leave one out" protocol, i.e., the procedure was repeatedly run where each iteration used the responses from one trial for testing and all remaining trials for training, until each trial had been used for testing once. The decoder's accuracy (percentage of correct responses) was used as a metric for performance. To assess significance, accuracy was compared with chance level (14.29\%, since there are seven categories).

To investigate the effect of signal and $R_{N C} s$ on the decoder's performance, we fit linear regressions to the distributions of signal and $R_{N C} s$ of each pair plotted against decoding accuracy. This tested how predictive the noise and signal correlations were of performance. We calculated the coefficient of determination $\left(R^{2}\right)$ to quantify the fraction of explained variance described by the regression. We used the built-in MatLab function "regress" (Mathworks) for parameter optimization.

\section{Results}

We recorded from five anesthetized owls of both sexes (four male and one female). Spatial tuning in free-field was measured with a high-density speaker array. The correlation structure [signal correlation $\left(\mathrm{R}_{\text {sig }}\right), \mathrm{R}_{N C}$ ], and spiking synchrony was assessed for pairs of simultaneously recorded neurons in each region. Correlation coefficients are reported as mean and standard deviation. All statistical tests performed are compiled in Table 1.

\section{Tuning properties of nearby units in OT}

Single units recorded from OT (19 recording sites, $n=$ 93 units) displayed well-delimited SpRFs (Fig. 2A), consistent with previous reports (Knudsen, 1982, 1984; 
Table 1. Summary of statistics

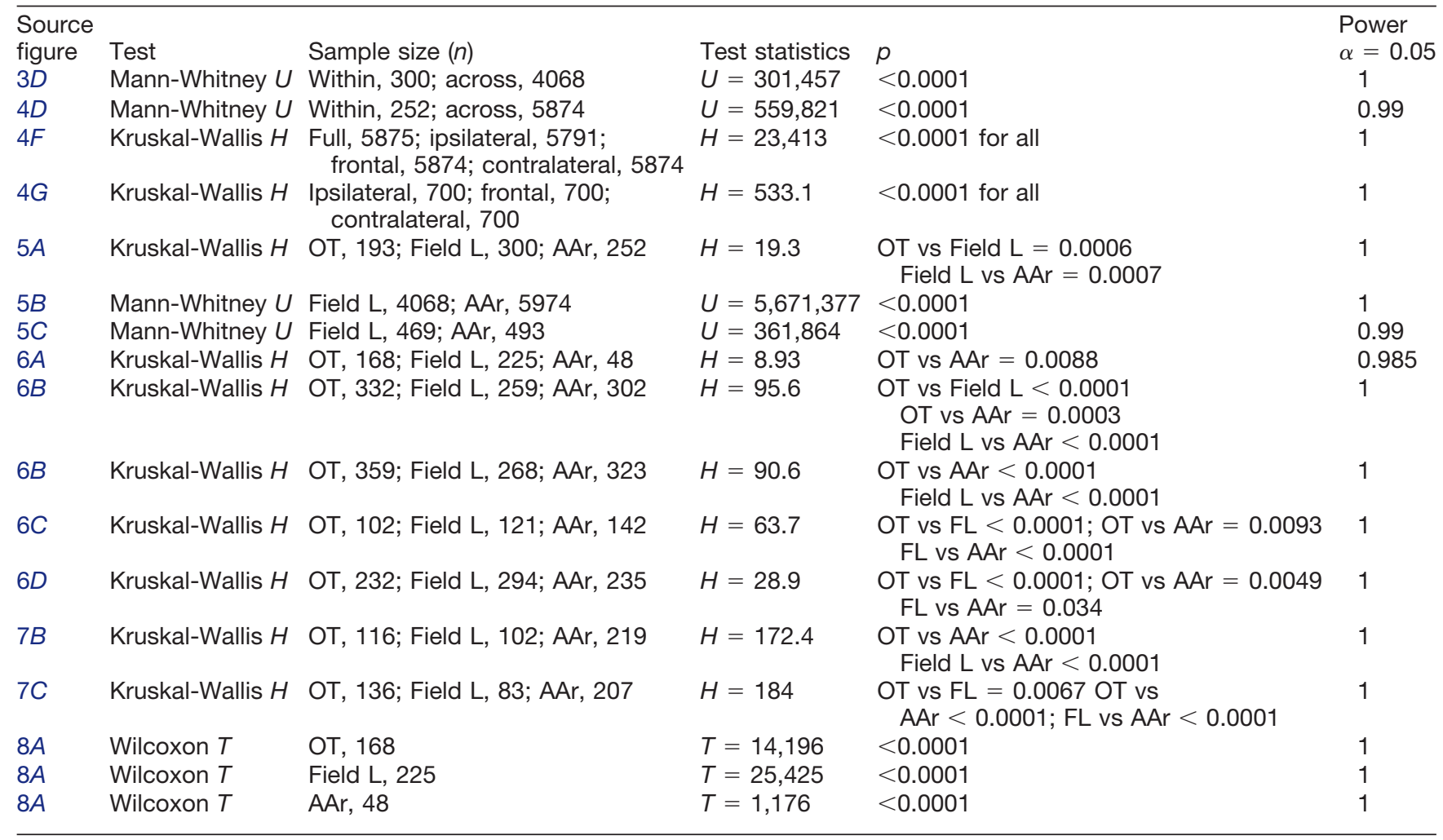

Test statistics; $U$ for Mann-Whitney, $H$ for Kruskal-Wallis, and $T$ for Wilcoxon.

Knudsen and Knudsen, 1983). Signal correlation analysis was used to assess the similarity of tuning properties for each pair of OT neurons in a recording site. Neighboring OT cells from the same recording site displayed similar tuning for azimuth $\left(R_{\text {sig }}=0.61 \pm 0.39, n=193\right.$ pairs); an example of one recording site is presented in Figure $2 \mathrm{C}$. The correlated tuning of neighboring cells in OT is consistent with the topographic representation of space, where nearby cells are tuned to nearby locations. Due to the topographic organization of spatial tuning in OT, the $\mathrm{R}_{\text {sig }}$ is expected to vary with distance between recording sites (Knudsen, 1982). to adequately quantify the signal correlation across recording sites in OT, a systematic recording of distant regions of OT would be necessary. Similar recordings have previously been performed (Knudsen, 1982) and were deemed beyond the scope of this study. Thus, signal correlation analysis across sites in OT was also judged beyond the current goal. Based on previous descriptions of OT, a dataset consisting of a systematic sampling would yield low signal correlations across sites.

\section{Tunings properties in Field $L$}

Azimuth tuning in Field $L$ (22 recording sites, $n=116$ units) was estimated by averaging SpRFs measured in free-field (Fig. 3A, top) across elevations (Fig. 3A, bottom). Tuning was less sharp than in OT as previously reported (Cohen and Knudsen, 1998). The preferred azimuth did not vary systematically along electrode tracks and between recording sites, consistent with previous reports that Field $L$ is nontopographically organized with respect to spatial tuning (Cohen and Knudsen, 1998). Field L neurons from the same recording site displayed similar tuning $\left(\mathrm{R}_{\text {sig }}=0.50 \pm 0.45, n=300\right.$ pairs; Fig. $3 C, D$, left), consistent with a clustered distribution previously reported (Cohen and Knudsen, 1998).

Additionally, signal correlation was calculated for pairs of Field $L$ neurons, across recording sites. $R_{s i g}$ in pairs of cells recorded from different recording sites was lower than in pairs from the same recording site $(0.10 \pm 0.46$, $n=4068$ pairs; $p<0.0001$, Mann-Whitney; Fig. $3 D$, right). The higher $R_{s i g}$ in nearby cells than in cells across recording sites indicates that the tuning is more similar in neighboring cells than across the population. This result further supports the reports that clusters of similarly tuned cells are randomly distributed across Field $\mathrm{L}$ (Cohen and Knudsen, 1998).

\section{Tunings properties in AAr}

AAr neurons (34 recording sites, $n=140$ units) showed characteristic azimuth tuning shapes (Fig. $4 A$ ), in agreement with previous reports (Cohen and Knudsen, 1995; Vonderschen and Wagner, 2009, 2012). Tuning curves displayed a transition from lower to higher firing rate across the midline, with lower responses to sounds in the ipsilateral space (Fig. 4A,C). Interestingly, this shape is evocative of hemispheric responses proposed by the twochannel rate-code theory for sound localization in mammals (Békésy, 1930; van Bergeijk, 1962; McAlpine et al., 
A Spatial receptive fields in Field $\mathrm{L}$
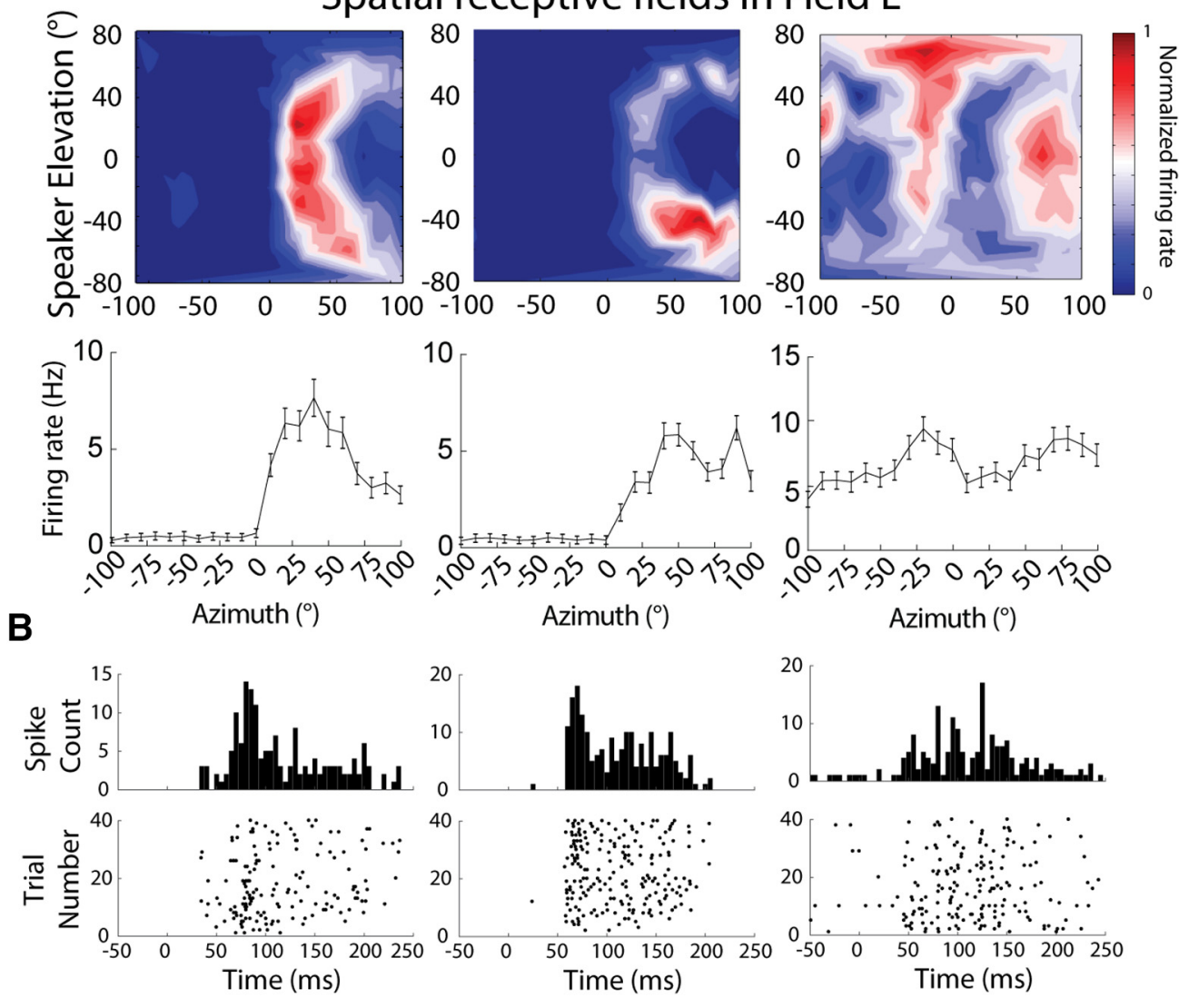

C Tuning curves of nearby cells

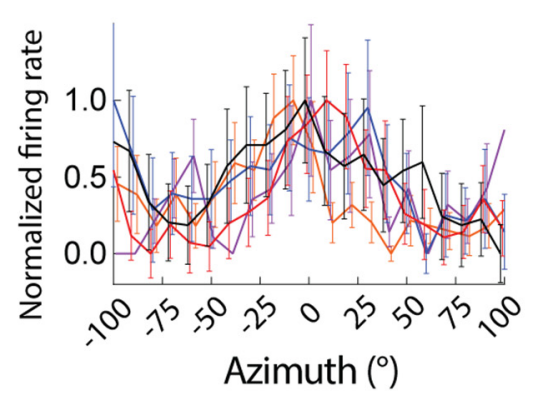

D Signal Correlation

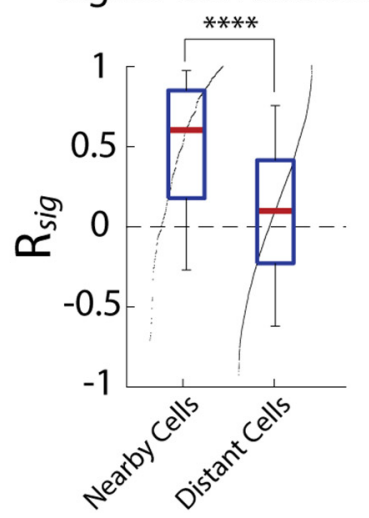

Figure 3. Azimuth tuning in Field L. $\boldsymbol{A}$, Example SpRFs (top) and azimuth tuning curves (bottom) of Field $\mathrm{L}$ neurons from different recording sites. $\boldsymbol{B}$, Peristimulus time histogram (PSTH; top) and rasters (bottom) for the spiking activity of the neurons in $\boldsymbol{A}$ for sounds from the speakers eliciting the maximal response. $\boldsymbol{C}$, Example azimuth tuning curves of neurons recorded from the same site (different neurons from $\boldsymbol{A}, \boldsymbol{B})$. Firing rates are normalized to facilitate comparison. Tuning curves represent mean $\pm S E M, 20-40$ repetitions. $\boldsymbol{D}, \mathrm{R}_{\text {sig }}$ for azimuth tuning of nearby cells (left) and cells from different recording sites (right). Box plots show median (red line), interquartile range (blue), and $5 \%$ and $95 \%$ quantiles (whiskers). Black dots indicate the sorted distribution of data points. Asterisks indicate statistical significance $(* * * * p<0.0001$; two-tailed Mann-Whitney $U$ test).

2001; Grothe et al., 2010). Consistently, $\mathrm{R}_{\text {sig }}$ was high for azimuth tuning ( $0.61 \pm 0.45, n=252$ pairs; Fig. $4 C, D$, left).

Unlike in Field L, similarity in azimuth tuning was also observed across AAr recording sites $\left(R_{\text {sig }}=0.52 \pm 0.40\right.$, $n=5874$ pairs; Fig. $4 D$, right, $E$ ), with maximal correlation of tuning curve shapes in the front (Fig. 4F). To quantify this observation, we compared signal correlation in the front $\left( \pm 40^{\circ}\right)$, contralateral $\left(+50^{\circ}\right.$ to $\left.+100^{\circ}\right)$, and ipsilateral $\left(-100^{\circ}\right.$ to $\left.-50^{\circ}\right)$ portions of azimuth tuning curves separately. $R_{\text {sig }}$ was significantly higher in frontal space $\left(R_{\text {sig }}=\right.$ $0.57 \pm 0.62)$ than the full azimuth range, ipsilateral $\left(R_{\text {sig }}=\right.$ $0.03 \pm 0.65)$, and contralateral space $\left(R_{\text {sig }}=0.33 \pm 0.65\right.$; 
A
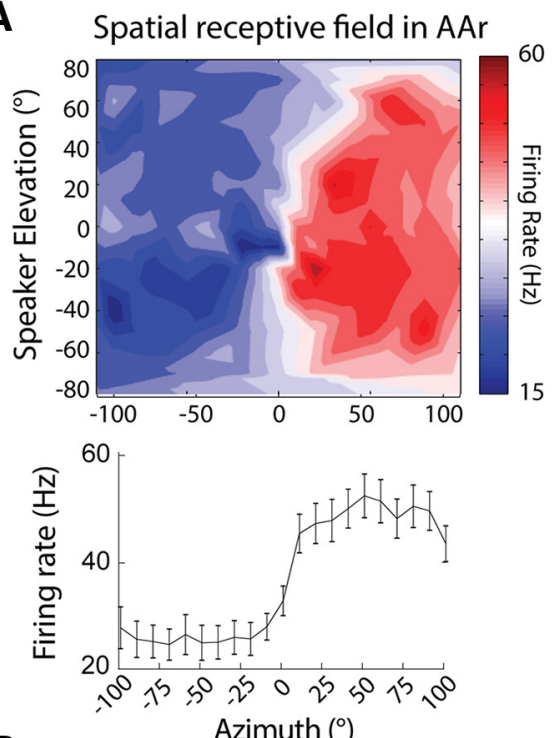

B

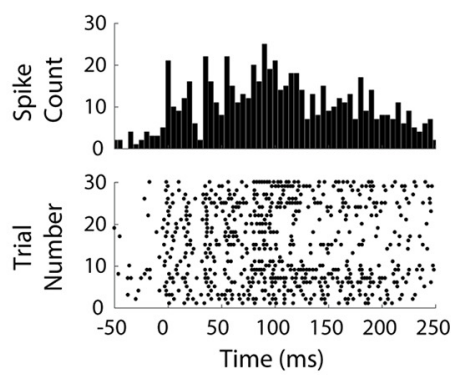

C
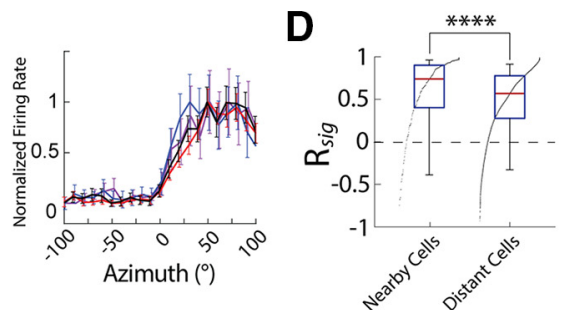

E

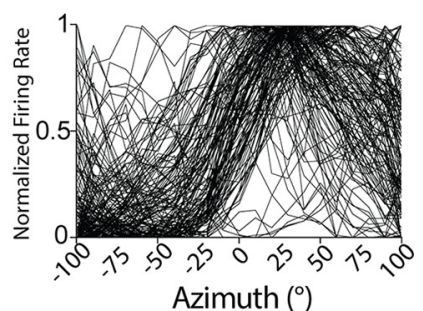

$\mathbf{F}$

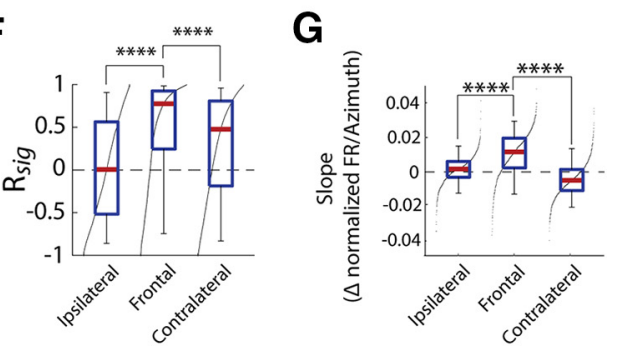

Figure 4. Spatial tuning in AAr. A, Example SpRF (top) and azimuth tuning curve (bottom). $\boldsymbol{B}$, Peristimulus time histogram (PSTH; top) and rasters (bottom) for the spiking activity of the neuron in $\boldsymbol{A}$, stimulated by sound from the speaker that elicited
Figure 4. continued

the maximal response ( $20^{\circ}$ azimuth and $-20^{\circ}$ elevation). C, Example azimuth tuning curves of neurons recorded from the same site. Curves show normalized firing (mean \pm SEM, 20-40 repetitions). $\boldsymbol{D}$, Signal correlation for azimuth tuning of nearby cells (left) and cells from different recording sites (right). $\boldsymbol{E}$, Overlaid azimuth tuning curves of all neurons in the AAr dataset. $\boldsymbol{F}$, Signal correlation within ipsilateral, frontal, and contralateral azimuth subregions of distant cells. G, Steepness (slope) of azimuth tuning curves within ipsilateral, frontal, and contralateral space. Box plots in $\boldsymbol{D}, \boldsymbol{F}, \boldsymbol{G}$ show median (red line), interquartile range (blue), and $5 \%$ and $95 \%$ quantiles (whiskers). Black dots indicate the sorted distribution of data points. $* * * * p<0.0001$. D, Two-tailed MannWhitney $U$ test; $\boldsymbol{F}, \boldsymbol{G}$, Kruskal-Wallis $H$ test with Dunn's multiple comparisons correction.

all comparisons $p<0.0001$, Kruskal-Wallis). Together, these data show higher $\mathrm{R}_{\text {sig }}$ in AAr with particularly high $\mathrm{R}_{\text {sig }}$ in the frontal space portion, across AAr neurons (Fig. $4 D$, right, $F$ ).

To characterize the information contained in AAr's tuning curves, we measured the slope of these curves (Paradiso, 1988; Seung and Sompolinsky, 1993). The region that was most similar for azimuth tuning, i.e., the front, also harbored the steepest slopes (frontal: $0.0098 \pm 0.0131$; ipsilateral: $0.0009 \pm 0.0087$; contralateral: $-0.0050 \pm 0.0105$ firing rate change/degree azimuth; all comparisons $p<0.0001$, Kruskal-Wallis; Fig. 4G). This finding demonstrates that not only is the frontal portion of space most similar across the whole population in AAr, but that this region may be the most informative about the stimulus location, which has also been proposed to be important for a rate code (McAlpine et al., 2001; Grothe et al., 2010).

Taken together, these results show uniform spatial tuning in AAr, with responses increasing from the ipsilateral to the contralateral side across the front. Additionally, tuning curves across the population were most correlated in the frontal portion of space, which was also the most informative (steeper slope) about auditory space.

\section{Signal correlation across structures}

In all regions tested, signal correlation was high in neighboring cells. This was anticipated, given the topographic organization in OT and the previously reported clusters of similarly tuned neurons in the forebrain (Cohen and Knudsen, 1995, 1998). Interestingly, signal correlation of nearby neurons in AAr was significantly higher than in Field L $(p=0.0007$, Kruskal-Wallis; Fig. $5 A)$. Moreover, signal correlation across recording sites was also significantly higher in AAr than in Field L $(p<0.0001$, MannWhitney; Fig. 5B). This suggests a transformation from a cluster organization in Field $L$ into a homogeneously tuned population in AAr. Recordings were targeted throughout the anatomic extent of AAr of multiple subjects. Because AAr does not display a topographic representation of auditory space (Cohen and Knudsen, 1995), the higher signal correlation across recording sites is unlikely due to over-sampling a particular region of AAr. Instead, these results indicate AAr neurons are more similarly tuned regardless of proximity. While the homogeneous tuning across AAr is not completely unexpected, as 


\section{A}

\section{Signal Correlation Within Recording Sites}

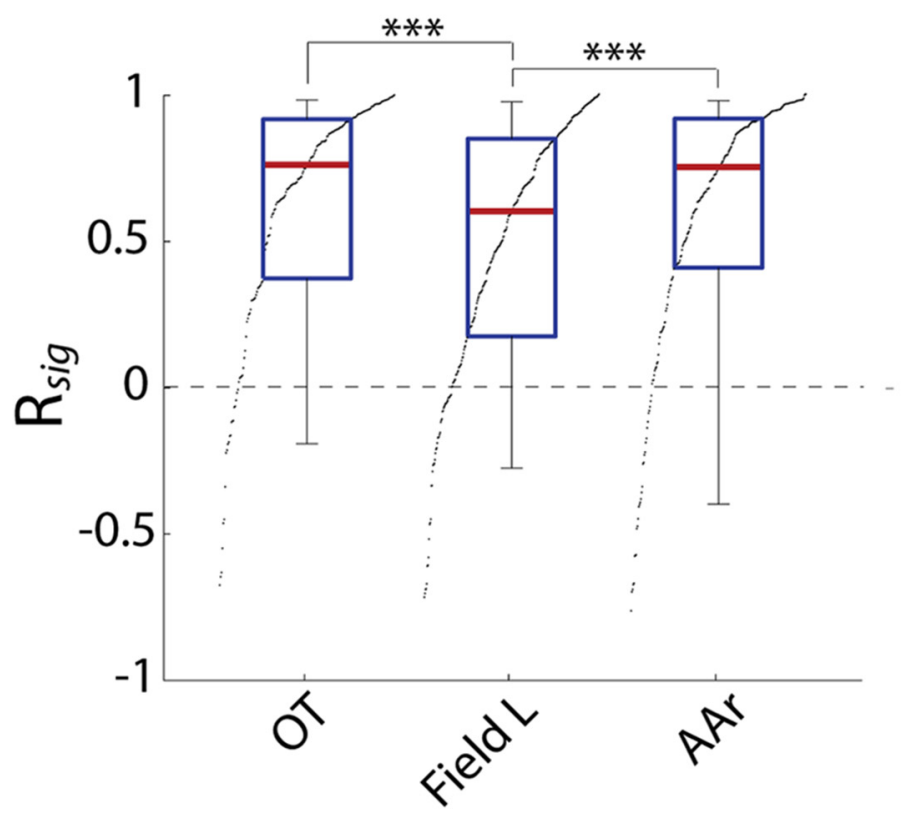

B

C

\section{Signal Correlation Across Recording Sites \\ Azimuth \\ ITD}

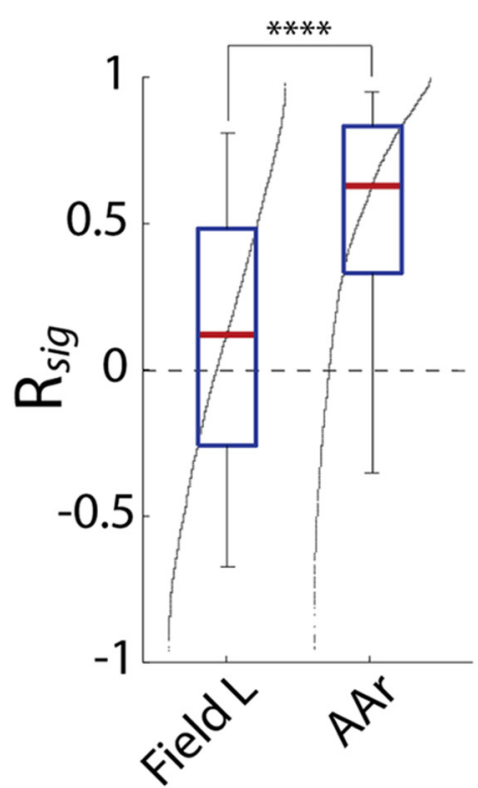

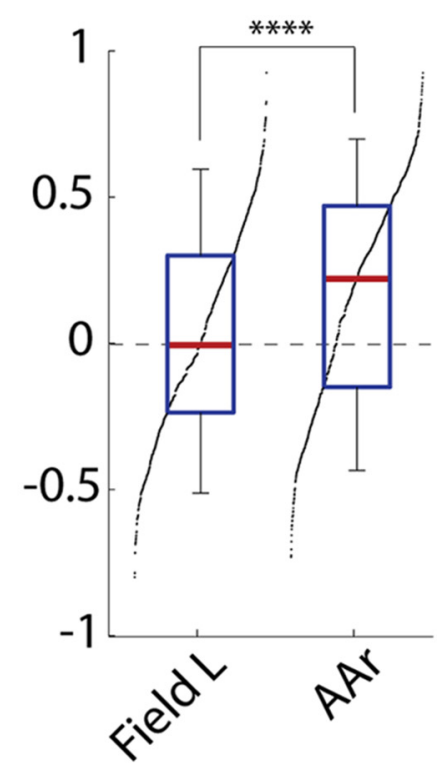

Figure 5. Comparison of signal correlation across brain regions. $\boldsymbol{A}$, Signal correlation in nearby cells for azimuth tuning. $\boldsymbol{B}, \boldsymbol{C}$, Signal correlation across recording sites, for azimuth $(\boldsymbol{B})$ and ITD $(\boldsymbol{C})$ tuning. The significantly stronger signal correlation across distant cells in AAr corroborates a more homogeneous tuning than in Field L. Box plots show median (red line), interquartile range (blue), and $5 \%$ and $95 \%$ quantiles (whiskers). Black dots indicate the sorted distribution of raw values. $* * * p<0.001, * * * * p<0.0001$. $\boldsymbol{A}$, Kruskal-Wallis $H$ test with Dunn's multiple comparisons correction; $\boldsymbol{B}, \boldsymbol{C}$, two-tailed Mann-Whitney $U$ test.

previous reports have noted the characteristic tuning shape and have described how it may form (Vonderschen and Wagner, 2012), it highlights the effect the correlation structure should have on coding. To further confirm the transformation from Field $L$ to AAr, we also compared the similarity of ITD tuning obtained with dichotic stimulation (AAr: 13 recording sites, 44 neurons; Field L: 10 recording sites, 46 neurons). Consistently, the ITD tuning was also 
significantly more similar across recording sites in AAr than Field $L$ (AAr: $R_{s i g}=0.18 \pm 0.39, n=493$ pairs; Field $\mathrm{L}: \mathrm{R}_{\text {sig }}=0.03 \pm 0.36, n=469$ pairs; $p<0.0001$, KruskalWallis), further demonstrating neurons across AAr display similar tuning (Fig. 5C). Overall, these results show a unique, homogeneous, organization of spatial tuning in AAr, which is different from both Field $L$ (clustered) and OT (topographic).

\section{$\mathbf{R}_{N C}$ across structures}

$\mathrm{R}_{N C}$ in simultaneously recorded neurons was assessed in all three structures by measuring the covariability of spike numbers elicited by repeated trials of frozen broadband noise. $R_{N C} S$ in OT were near values reported in studies in the visual cortex (Smith and Kohn, 2008; Ponce-Alvarez et al., 2013), somatosensory cortex (Okun et al., 2015), the songbird auditory forebrain (Jeanne et al., 2013), the mammalian A1 (Downer et al., 2015), and used in computational models (Cohen and Kohn, 2011; Kohn et al., 2016; $\mathrm{R}_{N C}=0.13 \pm 0.17, n=168$ pairs; KruskalWallis; Fig. $6 A$ ). $\mathrm{R}_{N C} \mathrm{~s}$ in AAr were significantly smaller than in OT $\left(\mathrm{R}_{N C}=0.06 \pm 0.13, n=48\right.$ pairs; OT vs AAr: $p=$ 0.0088 , Kruskal-Wallis; Fig. $6 A$ ). $R_{N C} s$ in Field L, on the other hand, were intermediate between OT and AAr, and not significantly different from either (Field $\mathrm{L}: \mathrm{R}_{N C}=$ $0.11 \pm 0.16, n=225$ pairs; Field L vs OT: $p=0.54$, Field L vs AAr: $p=0.08$; Kruskal-Wallis; Fig. $6 A$ ). These results show lower $\mathrm{R}_{N C} \mathrm{~s}$ in $A A r$ than in the midbrain.

Next, we tested potential causes of low $R_{N C} S$ in the forebrain. Mathematically, $R_{N C} S$ are independent from firing rate. However, biological mechanisms such as the spiking threshold nonlinearity, may induce lower $R_{N C} s$ at low firing rates (Cohen and Kohn, 2011). Additionally, an in vitro study has demonstrated that $\mathrm{R}_{N C} \mathrm{~s}$ are higher for neurons with higher firing rates (de la Rocha et al., 2007). To test if firing rates could explain the lower $R_{N C} S$ in the forebrain, the spontaneous and evoked firing rates were compared across structures (Fig. 6B). AAr's firing rate was significantly higher than both Field $\mathrm{L}$ and OT and Field L's spontaneous firing rate was significantly lower than in the other structures (spontaneous firing rate: OT = $9.83 \pm 17.13$; Field $\mathrm{L}=4.45 \pm 5.74 ; \mathrm{AAr}=23.54 \pm 48.47$; evoked firing rate: $\mathrm{OT}=29.11 \pm 43.75$; Field $\mathrm{L}=16.24 \pm$ 17.30; $\mathrm{AAr}=57.87 \pm 80.27$ spikes/s; spontaneous OT vs AAr: $p=0.0003$; evoked OT vs Field L: $p=0.059$; all other comparisons; $p<0.0001$, Kruskal-Wallis; Fig. 6B). While the comparatively low $R_{N C} S$ observed in Field $L$ could be attributed to a low firing rate, the higher firing rate in AAr cannot explain its significantly reduced $R_{N C}$.

Because $R_{N C}$ is inversely related to the standard deviation of individual responses and directly related to covariance, low $R_{N C}$ can result from increased variance, decreased covariance, or both. While single-cell mechanisms may drive the variance of individual cell responses, the covariance may reflect properties of network architecture such as shared inputs. We therefore examined response variance and covariance across the dataset. Interestingly, individual AAr neurons displayed significantly higher variance, compared with OT and Field L [OT: $0.66 \pm 1.49$; Field L: $0.29 \pm 0.35$; AAr: $1.08 \pm 1.69$ firing
A
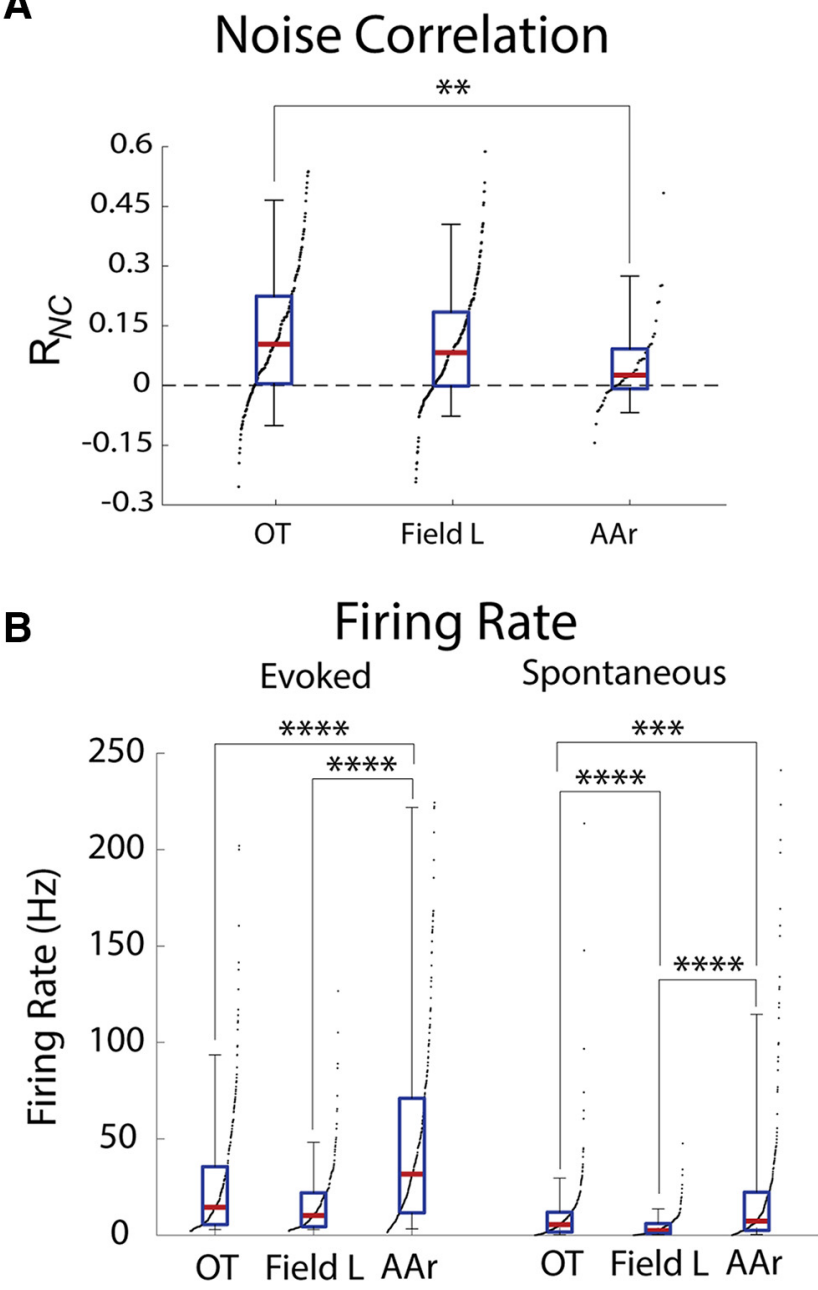

C
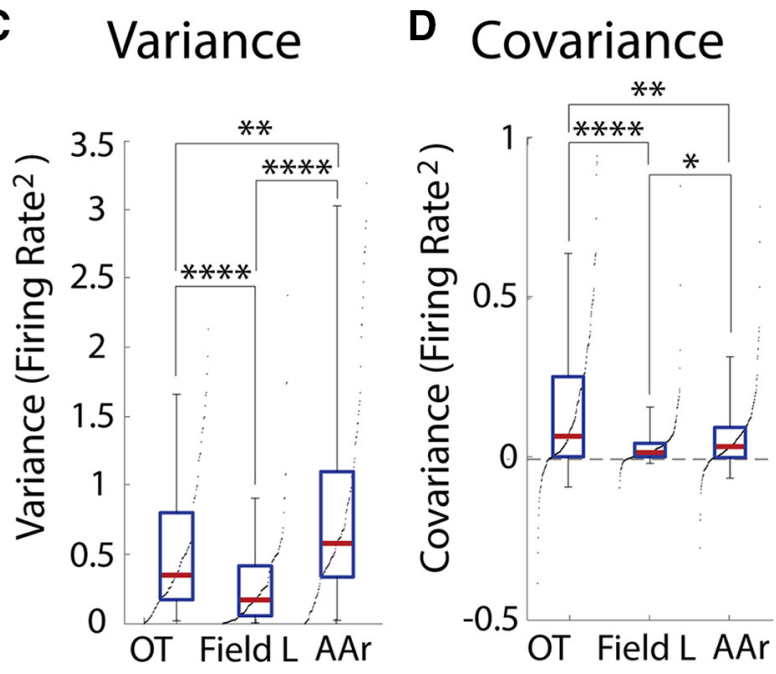

Figure 6. Comparison of $\mathrm{R}_{N C} \mathrm{~s}$. $\boldsymbol{A}, \mathrm{R}_{N C} \mathrm{~s}$ in $\mathrm{OT}$, Field L, and $\mathrm{AAr}$. $\boldsymbol{B}$, Average firing rates of OT, Field $L$, and AAr cells during sound presentation (left) and spontaneous firing (right). C, $\boldsymbol{D}$, Average variance $(\boldsymbol{C})$ and covariance $(\boldsymbol{D})$ in OT, Field $L$, and AAr neurons. Box plots represent median (red line), interquartile range (blue), and $5 \%$ and $95 \%$ quantiles (whiskers). Black dots indicate the sorted distribution of raw values. $* p<0.05$, $* * p<0.01$, 
continued

$* * * p<0.001$, **** $p<0.0001$; Kruskal-Wallis $H$ test with Dunn's multiple comparisons correction.

rate (spikes/s) ${ }^{2}$; both comparisons; $p<0.0001$, KruskalWallis; Fig. 6C] and significantly lower covariance than OT [OT: $0.17 \pm 0.30$; Field L: $0.04 \pm 0.07$; AAr: $0.08 \pm 0.19$ firing rate (spikes/s) ${ }^{2}$; OT vs AAr: $p=0.0095$, Field $L$ vs AAr: $p=0.045$ Kruskal-Wallis; Fig. $6 D$ ]. Therefore, the low $\mathrm{R}_{N C}$ in AAr results from both increased variability of individual neurons' responses and reduced covariability, suggesting that single-cell and network mechanisms impact $\mathrm{R}_{N C} \mathrm{~s}$.

\section{Spike synchrony across structures}

To achieve further insight into mechanisms underlying the different correlation structures observed in midbrain and forebrain, spike synchrony was computed for all pairs of simultaneously recorded neurons. Spike synchrony has been linked to shared connections between neurons (Atencio and Schreiner, 2013; Miller et al., 2014; Atencio et al., 2016; Sabri et al., 2016; Schwab et al., 2017; Yaeger and Trussell, 2016). Thus, lack of shared connections between neurons could underlie the low $R_{N C}$ in the forebrain. To assess the synchrony of spikes in pairs of neurons, CCGs were calculated from simultaneously recorded spike trains. Synchrony was then quantified by taking the integral of the peak at 0-lag. The peak's boundaries were set at half maximum response. Synchrony was significantly different for all three regions with OT displaying the highest synchrony and AAr displaying the lowest [peak CCG integral: OT $=0.00052 \pm 0.00054, n=116$ pairs; Field $\mathrm{L}=0.00025 \pm 0.00038, n=102$ pairs; $\mathrm{AAr}=$ $0.000032 \pm 0.00019$ coincidences $*$ ms $/$ spike, $n=219$ pairs; OT vs FL: $p=0.0067$, OT vs AAr: $p<0.0001$, Field $L$ vs AAr: Kruskal-Wallis; Fig. 7A, left, $B$ ]. Synchrony during spontaneous activity was similar in Field $\mathrm{L}$ and $\mathrm{OT}$ and both were larger than in AAr (OT $=0.00091 \pm 0.00058$, $n=136$; peak CCG: Field $\mathrm{L}=0.00100 \pm 0.00062, n=83$; $\mathrm{AAr}=0.00016 \pm 0.0006$ coincidences $* \mathrm{~ms} / \mathrm{spike}, n=$ 207; OT vs Field L: $p>0.9999$, OT vs AAr: $p<0.0001$, Field L vs AAr: $p<0.0001$, Kruskal-Wallis; Fig. $7 A$, right, $C)$. Synchrony was lower during evoked than spontaneous spiking for both OT and Field L (spontaneous vs evoked: OT, $p=0.03$; Field L, $p<0.0001$; KruskalWallis). Decreased synchrony from spontaneous to evoked responses has been observed in other brain regions (Tsodyks et al., 1999; Kohn and Smith, 2005). AAr did not display this relationship, likely due to a floor effect, as synchrony during spontaneous spiking was already close to zero. Therefore, nearby neurons in AAr, although having similar tuning, fired spikes in a remarkably independent fashion, suggesting lack of shared input. Similar to $R_{N C} s$, synchrony measured with CCGs is also influenced by firing rate. In particular, higher firing rates increase the number of coincidences and elevate the magnitude of the center peak of the CCG, artificially increasing synchrony, even with normalization (de la Rocha et al., 2007; Smith and Kohn, 2008). As was shown in Figure $6 B$, AAr neurons displayed higher firing rates than OT and Field $\mathrm{L}$. Therefore, as was the case for $\mathrm{R}_{N C} \mathrm{~S}$, the reduced synchrony in AAr cannot be explained by differences in firing rates.

\section{Effect of correlations on information decoding}

Previous studies have shown dramatic effects of the correlation structure on the amount of information a neural system can encode (Averbeck and Lee, 2006; Averbeck et al., 2006). In particular, high $R_{N C} s$ may limit the amount of information in a population with high signal correlations. Additionally, $\mathrm{R}_{N C}$ limits information in ratecode schemes (Sompolinsky et al., 2001; Zohar et al., 2013). To assess whether the different correlation structures in the midbrain and forebrain may have consequences on coding we estimated the accuracy of simultaneously recorded pairs of neurons in encoding azimuth, using linear discriminant analysis (Materials and Methods). This decoder considers the spike counts while attempting to determine the optimal decoding strategy. This strategy allows the decoder to use the biological $\mathrm{R}_{N C} \mathrm{~s}$. However, limiting the decoding estimate to pairs of neurons reduces information. Additionally, most simultaneously recorded neurons displayed similar tuning, suggesting their responses carry overlapping information. Both of these factors would inherently make the decoder perform worse. Impressively, even with these limitations, the classifier identified the azimuth above chance levels in all three regions (OT: $21.21 \pm 4.59 \%$; Field L: $17.23 \pm$ 3.57\%; AAr: $20.53 \pm 4.37 \%$; $p<0.0001$, Wilcoxon signed-rank; Fig. $8 A$ ).

Decoding performance can be dictated by numerous factors (e.g., variance, tuning shape, steepness of curves), including the correlation structure. For example, high signal and $\mathrm{R}_{N C} \mathrm{~S}$ together can impair performance (Averbeck et al., 2006). Multilinear regression analysis was used to quantify how predictive the correlation structure was of the decoder's accuracy, an assessment of the effect of correlation structure on the readout of the population. Signal and $R_{N C}$ S could explain $18 \%$ and $16 \%$ of the variance of the decoding performance for OT and Field L, respectively (Fig. 8B,C). This suggests that noise and signal correlations have a significant effect on decoding accuracy. In particular, good classification was associated with stronger signal and weaker $\mathrm{R}_{N C} \mathrm{~s}$, reflecting that high $\mathrm{R}_{N C}$ limits information carried in the firing rate of populations of neurons with similar tuning. Interestingly, this trend was not observed in AAr. Here 19\% of the variance of the decoding performance could be explained by signal correlation alone (Fig. $8 D$ ). Including $\mathrm{R}_{N C}$ did not increase the predictive power of the model $\left(R^{2}=0.19\right.$ with both signal and $R_{N C} S$ ), likely due to the narrow range of $\mathrm{R}_{N C} \mathrm{~S}$ observed in AAr with mean close to zero. This suggests that while $R_{N C} s$ were detrimental for OT and Field $L$, they were of no consequence in AAr. Thus, the low $R_{N C} s$ in AAr may be beneficial for coding by restricting the information-limiting effect of $\mathrm{R}_{N C} \mathrm{~s}$.

In sum, these results demonstrate a different correlation structure in the midbrain and forebrain (Fig. 9). Nearby neurons in OT were more similarly tuned than in the forebrain, with strongly correlated tuning, firing rate vari- 
A

Cross-correlograms (CCGs)

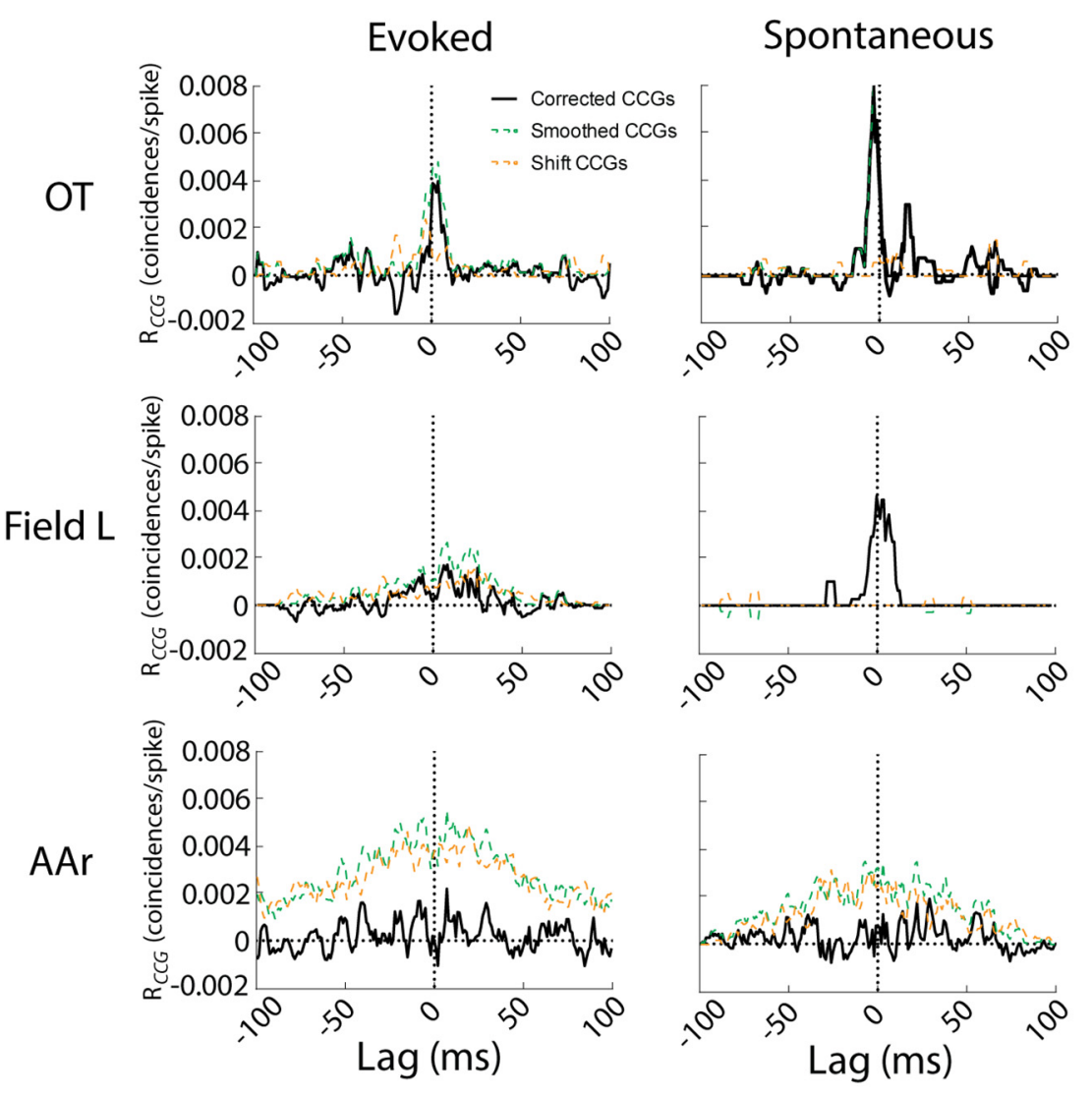

\section{Synchrony across regions}

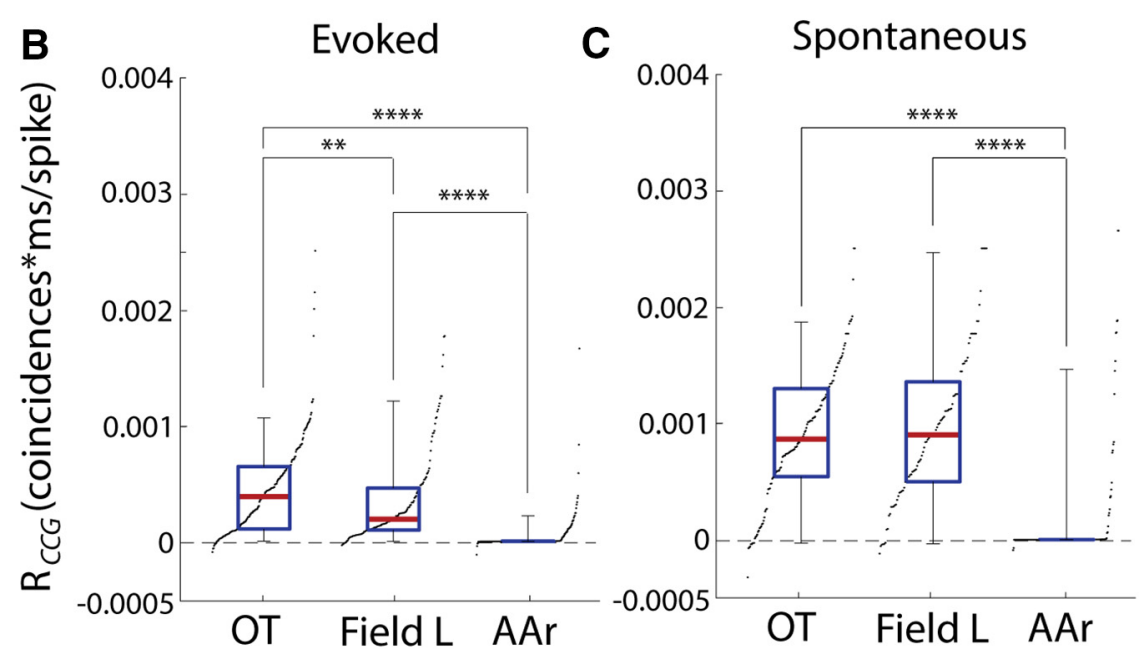

Figure 7. Spike-time synchrony in OT, Field L, and AAr. A, Example CCGs for pairs of evoked (left) and spontaneous (right) responses in OT (top), Field L (middle), and AAr (bottom). The corrected CCGs for individual pairs of neurons (solid black) are overlaid to the smoothed CCG (dashed green) and shifted CCG (dashed orange). The plots for left and right are from the same pair. $\boldsymbol{B}, \boldsymbol{C}$, Statistical comparison of synchrony across brain regions for evoked $(\boldsymbol{B})$ and spontaneous $(\boldsymbol{C})$ spikes. Box plots represent median (red line), interquartile range (blue), and $5 \%$ and $95 \%$ quantiles (whiskers). Black dots indicate the sorted data; $* * p<0.01, * * * * p<0.0001$; Kruskal-Wallis $H$ test with Dunn's multiple comparisons correction.

ability, and spike timing. In the forebrain, on the other hand, Field L contained clusters of similarly tuned neurons distributed randomly. Whereas AAr neurons were more uniformly tuned, with their firing rate increasing from ipsilateral 
A

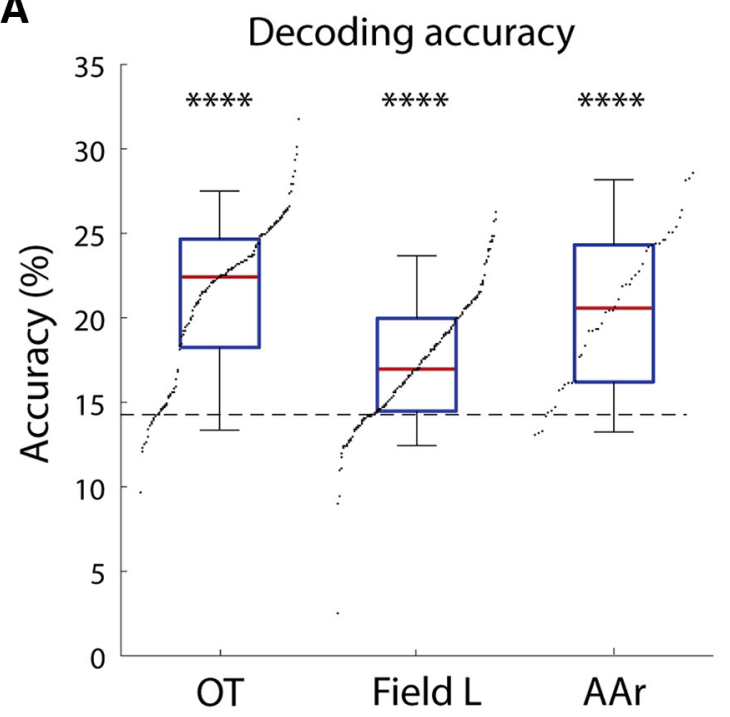

B

\section{Multilinear regression analysis}

OT

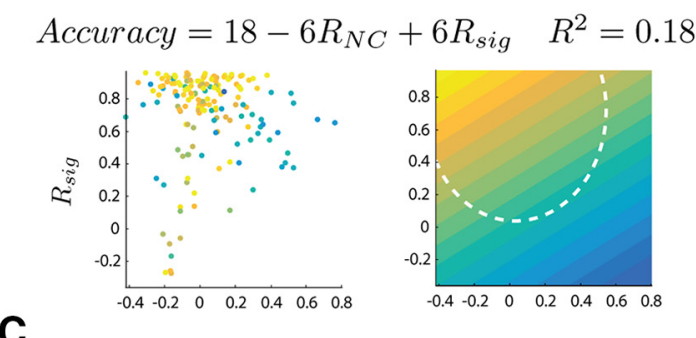

Field $\mathrm{L}$

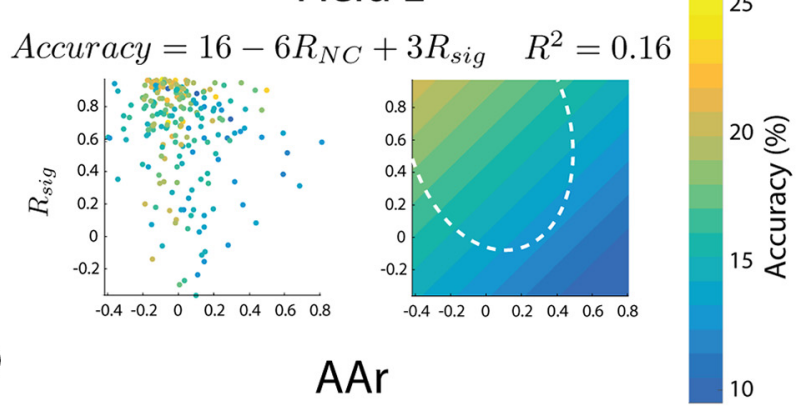

Accuracy $=16+6 R_{\text {sig }} \quad R^{2}=0.19$
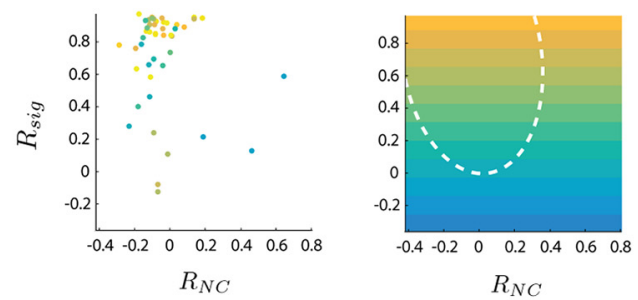

Figure 8. Decoding of ITD and azimuth from firing rate. $\boldsymbol{A}$, Decoding accuracy in pairs of simultaneously recorded units in OT, Field $\mathrm{L}$, and AAr. Box plots represent median (red line), interquartile range (blue), and 5\% and 95\% quantiles (whiskers). Asterisks indicate better than chance level decoding of azimuth (dashed line: $14.92^{\circ}$ ). Dots are the sorted data points. $\boldsymbol{B}-\boldsymbol{D}$, left, Decoder performance

\section{Figure 8. continued}

(colored points) plotted against signal $\left(R_{\text {sig }}\right)$ and $R_{N C}$ for each pair of neurons in OT (B), Field L $(\boldsymbol{C})$, and $A A r(\boldsymbol{D})$. Point color indicates level of accuracy (color bar on the right). Right, Linear fit of accuracy data as a function of signal and $R_{N C}$. White dashed ellipsoids depict $95 \%$ range of signal and $R_{N C} s$ used for the linear fit, which avoided outliers. Fit functions and $R^{2}$ values are shown above each plot. Color bar matches all plots $(* * * * p<0.0001$; Wilcoxon signed-rank test).

to contralateral space across the front, but displaying uncorrelated variability and timing. While the correlation structure in the midbrain can be explained by shared inputs of nearby cells in a topographic representation, the forebrain neurons responded more independently over time, suggesting decreased shared inputs. Our decoding approach showed that this unique correlation structure in AAr is advantageous under the two-channel rate-code scheme of sound location (van Bergeijk, 1962; McAlpine et al., 2001; Grothe et al., 2010).

\section{Discussion}

We found distinct correlation structure in the owl's auditory midbrain and forebrain, characterized primarily by significantly lower $R_{N C}$ in the forebrain. In particular, a unique correlation structure emerges in AAr, with high signal correlation between nearby and also distant cells, but low $R_{N C}$. Thus, the tuning of AAr neurons is uniform across the population while variability is decorrelated. A decoder model shows this correlation structure can limit the effect of $R_{N C}$ on information. Interestingly, the tuning shape in AAr is reminiscent of the two-channel rate code for sound localization (van Bergeijk, 1962; McAlpine et al., 2001; Grothe et al., 2010). Thus, the AAr correlation structure may be beneficial for reliable rate coding of auditory space in the forebrain.

\section{Emergence of uniform tuning in the forebrain}

The high signal correlation in nearby neurons in OT and Field $L$ corroborates reports of similar tuning of nearby cells in both structures. While the map of auditory space in OT determines that nearby cells are tuned to nearby positions in space (Knudsen, 1982), previous studies have reported clusters of similarly tuned neurons in Field $L$ with no topographic organization which have been compared with cortical columns (Cohen and Knudsen, 1995, 1998). The low signal correlation across recording sites in Field $L$ supports the cluster hypothesis. On the other hand, AAr showed strong signal correlations within and across recording sites, indicating that the tuning is homogeneous across the population. These results provide further evidence supporting previous descriptions of tuning in OT and Field L, while highlighting $\mathrm{AAr}$ as a more homogeneous population.

\section{Emergence of uncorrelated firing in the forebrain}

Response covariability of nearby neurons in OT, Field L, and AAr differed. Variability in OT was correlated and spikes were synchronous, suggesting neighboring OT cells share inputs (Smith and Kohn, 2008; Smith and Sommer, 2013; Downer et al., 2015). 
OT

Topographic
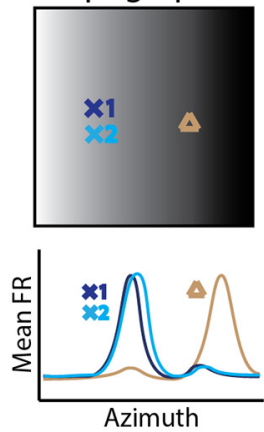

\section{Signal correlation}

Distant neurons

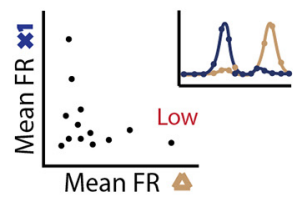

Nearby neurons
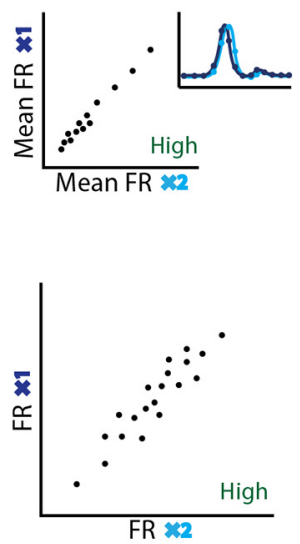

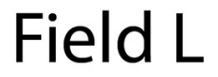

Clustered
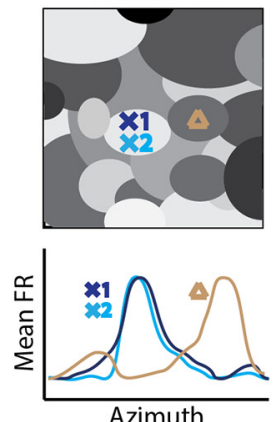

Azimuth
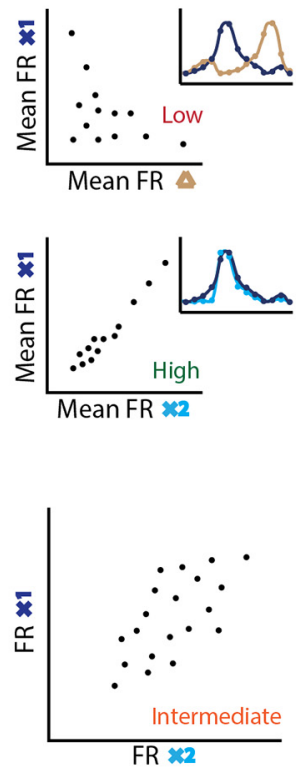

AAr

Uniform
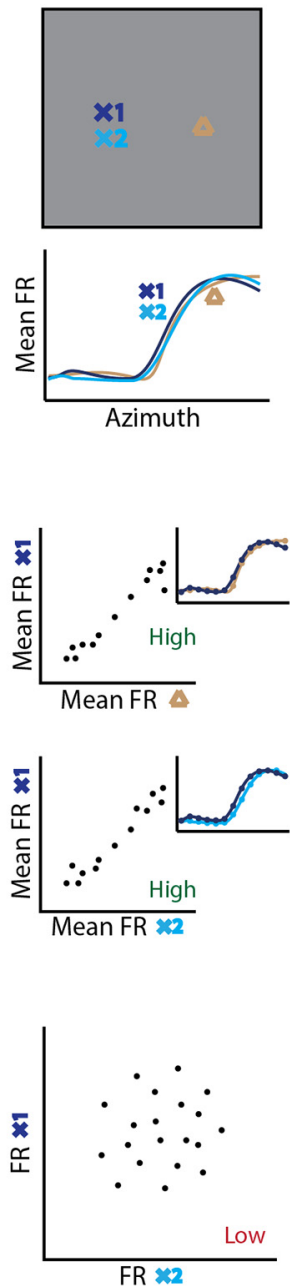

Figure 9. Summary of findings. Top, Large-scale spatial tuning organization of each region (above) and corresponding schematic tuning curves at recording locations (below) denoted by crosses (X1 and X2 represent nearby sites) and triangles representing a distant site. OT displays a topographic organization of spatial tuning, while Field $L$ is organized in clusters. AAr displays uniform tuning. Middle, Signal correlation for distant (above) and nearby (below) neurons. Tuning curves of distant sites is different in OT (extrapolated from previous descriptions) and Field L but similar in AAr (insets). On the other hand, tuning curves of nearby neurons are similar in all three structures. Scatter plots represent firing rates (FR) of pairs of cells across azimuth plotted against one another, used to calculate signal correlation. Tuning curves are shown in the insets. Bottom, Schematic scatter plots representing the correlated FR variability of nearby cells in OT, intermediate level of FR variability in Field L, and uncorrelated FR variability in AAr.

Because low firing rates have been associated to lower $\mathrm{R}_{N C} \mathrm{~S}$ (de la Rocha et al., 2007; Cohen and Kohn, 2011), it is possible that the lower $R_{N C}$ in Field $L$ results from an effect of the spiking nonlinearity on correlated but weak subthreshold inputs. Field L neurons also displayed synchronous spontaneous spiking; suggesting these neurons may receive shared thalamic input. However, synchrony was reduced in evoked spikes. Increased decorrelation in stimulus-driven responses has been reported (Tsodyks et al., 1999; Kohn and Smith, 2005).

Interestingly, AAr neurons displayed high firing rate, while correlated variability, $R_{N C}$ and synchrony, were close to zero. This suggests that mechanisms to dampen $\mathrm{R}_{N C}$ may exist in AAr. Both network and cellular mecha- nisms can reduce $\mathrm{R}_{N C}$ (Shadlen and Newsome, 1998; Azouz and Gray, 1999; Wiechert et al., 2010; Ribrault et al., 2011; Tetzlaff et al., 2012; Grytskyy et al., 2013; Herrero et al., 2013; Goris et al., 2014; Chelaru and Dragoi, 2016; von Trapp et al., 2016). The analysis of variance and covariance can provide insight into what mechanisms may be in place. In AAr, the covariance was low while the variance of individual neuron responses was high, both of which would result in low $\mathrm{R}_{N C} \mathrm{~s}$. Thus, mechanisms influencing both the variability of responses of individual neurons and the joint variability of pairs of neurons may be in place. For example, recurrent inhibition (Wiechert et al., 2010; Tetzlaff et al., 2012; Grytskyy et al., 2013; Chelaru and Dragoi, 2016) and higher variability of synaptic re- 
lease (Ribrault et al., 2011) have been demonstrated to reduce $R_{N C} S$ and are viable mechanisms for AAr. Recurrent inhibition could be implemented in AAr through reciprocal connections across hemispheres, or feedback from one of AAr's downstream targets (Knudsen et al., 1995). Another potential mechanism may be lack of shared inputs, which are suggested by the low synchrony in AAr. Further investigation of the circuit and cellular properties of AAr neurons is necessary to fully understand the mechanisms underlying uncorrelated firing in AAr.

Recordings were performed on anesthetized owls. This eliminated the effect of changes in alertness on $R_{N C} s$ (Cohen and Maunsell, 2009; Herrero et al., 2013). However, anesthesia has been shown to differently affect forebrain and midbrain responses. Specifically, the spectrotemporal tuning of midbrain responses remain largely unaffected by anesthesia while it broadens in the forebrain (Capsius and Leppelsack, 1996; Alkire and Miller, 2005; Schumacher et al., 2011; Karino et al., 2016). Thus, it is possible the different $R_{N C} s$ in midbrain and forebrain could be generated through a differential effect of anesthesia. However, previous work has reported anesthesia increases $R_{N C} S$ in the forebrain by generating large "up and down" states of activity and quiescent periods (Ecker et al., 2014). While our recordings did not display such activity patterns, this effect would be inconsistent with the reduced $R_{N C}$ we observed in the forebrain.

\section{Correlation structure of the forebrain and implications for coding}

Our results demonstrate that OT, Field L, and AAr have strikingly different correlation structures. Because correlated firing determines information, these differences may carry important implications for coding of auditory space in the midbrain and forebrain.

Tuning curves of AAr neurons showed the strongest signal correlation in the front, with a sharp transition from low firing rates in ipsilateral space to higher in contralateral space. The transition across the midline is reminiscent of the two-channel rate code. This hypothetical code relies on the average firing rate of two hemispheric populations and discriminates with greatest precision stimulus located in the front, the region of steepest slope (Békésy, 1930; van Bergeijk, 1962; Grothe et al., 2010; Razak, 2011; Lee and Groh, 2014; Briley et al., 2016). Correlated activity can greatly affect average responses of a uniformly tuned population (Zohary et al., 1994; Shadlen and Newsome, 1998; Zohar et al., 2013; Kohn et al., 2016), hindering the system's discriminability. Therefore, the reduced $R_{N C} s$ in $A A r$ are beneficial for a rate-code system. Additionally, we showed that $R_{N C} s$ are detrimental for decoding of sound source azimuthal location, and that the low $\mathrm{R}_{N C}$ in AAr limits this effect. Taken together, these results demonstrate that a rate-code scheme would benefit from AAr's correlation structure.

The presence or absence of maps of auditory space in the brain has mystified researchers, leading to different theories of how sound direction is represented (Békésy, 1930; Jeffress, 1948; McAlpine et al., 2001; Schnupp and Carr, 2009). Whereas maps have been associated to place code, a rate code has been suggested to explain the lack of it (Konishi, 2003; Schnupp and Carr, 2009; Grothe et al., 2010). Responses in the forebrain are reminiscent of the two-channel rate code proposed for rodents (McAlpine et al., 2001; Grothe et al., 2010) and humans (Briley et al., 2013; Derey et al., 2016; Dykstra et al., 2016; McLaughlin et al., 2016). Thus, our findings may generalize to other species. Our results provide support to the notion that auditory forebrain regions involved in sound localization, which do not exhibit a map, display a correlation structure favorable to a rate code.

\section{Concluding remarks}

The comparative analysis throughout the owl's sound localization system showed differences between the correlation structure in midbrain and forebrain. These findings permit a glimpse into how auditory space may be encoded in the forebrain, where a population with homogenous tuning but uncorrelated variability emerges. This correlation structure is beneficial under a rate-code framework. Additional evidence for the existence of the rate code and mapping the anatomic connections will be necessary to further test this hypothesis. These findings can be applicable to other species, as the topographic representation of auditory space in the superior colliculus (Cynader and Berman, 1972; Gordon, 1973; Knudsen, 1982; Palmer and King, 1982; Middlebrooks and Knudsen, 1984) and nontopographic in the forebrain exist in all species studied (Eisenman, 1974; Benson et al., 1981; Middlebrooks and Pettigrew, 1981; Imig et al., 1990; Rajan et al., 1990; Carr and Christensen-Dalsgaard, 2015; Razak et al., 2015; McLaughlin et al., 2016), and the two-channel rate code has been proposed for mammalian species (McAlpine et al., 2001; Derey et al., 2016).

\section{References}

Alkire MT, Miller J (2005) General anesthesia and the neural correlates of consciousness. Prog Brain Res 150:229-244. CrossRef Medline

Atencio CA, Schreiner CE (2013) Auditory cortical local subnetworks are characterized by sharply synchronous activity. J Neurosci 33:18503-18514. CrossRef Medline

Atencio CA, Shen V, Schreiner CE (2016) Synchrony, connectivity, and functional similarity in auditory midbrain local circuits. Neuroscience 335:30-53. CrossRef Medline

Averbeck BB, Latham PE, Pouget A (2006) Neural correlations, population coding and computation. Nat Rev Neurosci 7:358-366. CrossRef Medline

Averbeck BB, Lee D (2006) Effects of noise correlations on information encoding and decoding. J Neurophysiol 95:3633-3644. CrossRef Medline

Azouz R, Gray CM (1999) Cellular mechanisms contributing to response variability of cortical neurons in vivo. J Neurosci 19:22092223.

Bair W, Zohary E, Newsome WT (2001) Correlated firing in macaque visual area MT: time scales and relationship to behavior. J Neurosci 21:1676-1697. Medline

Békésy VG (1930) Zur Theorie des Hörens. Über das Richtungshören bei einer Zeitdifferenz oder Lautstärkenungleichheit der beiderseitigen Schalleinwirkungen. Physik Z 31:824-835.

Belliveau LAC, Lyamzin DR, Lesica NA (2014) The neural representation of interaural time differences in gerbils is transformed from midbrain to cortex. J Neurosci 34:16796-16808. CrossRef Medline 
Benson DA, Hienz RD, Goldstein MH (1981) Single-unit activity in the auditory cortex of monkeys actively localizing sound sources: spatial tuning and behavioral dependency. Brain Res 219:249267. Medline

Briley PM, Goman AM, Summerfield AQ (2016) Physiological evidence for a midline spatial channel in human auditory cortex. $\mathrm{J}$ Assoc Res Otolaryngol 17:331-340. CrossRef Medline

Briley PM, Kitterick PT, Summerfield AQ (2013) Evidence for opponent process analysis of sound source location in humans. J Assoc Res Otolaryngol 14:83-101. CrossRef Medline

Butts DA, Goldman MS (2006) Tuning curves, neuronal variability, and sensory coding. PLoS Biol 4:e92. CrossRef Medline

Capsius B, Leppelsack HJ (1996) Influence of urethane anesthesia on neural processing in the auditory cortex analogue of a songbird. Hear Res 96:59-70. Medline

Carr CE, Christensen-Dalsgaard J (2015) Sound localization strategies in three predators. Brain Behav Evol 86:17-27. CrossRef Medline

Cazettes F, Fischer BJ, Pena JL (2014) Spatial cue reliability drives frequency tuning in the barn owl's midbrain. Elife 3:e04854. CrossRef Medline

Cazettes F, Fischer BJ, Peña JL (2016) Cue reliability represented in the shape of tuning curves in the owl's sound localization system. J Neurosci 36:2101-2110. CrossRef Medline

Chelaru MI, Dragoi V (2016) Negative correlations in visual cortical networks. Cereb Cortex 26:246-256. CrossRef Medline

Cohen MR, Kohn A (2011) Measuring and interpreting neuronal correlations. Nat Neurosci 14:811-819. CrossRef Medline

Cohen MR, Maunsell JHR (2009) Attention improves performance primarily by reducing interneuronal correlations. Nat Neurosci 12: 1594-1600. CrossRef Medline

Cohen YE, Knudsen El (1995) Binaural tuning of auditory units in the forebrain archistriatal gaze fields of the barn owl: local organization but no space map. J Neurosci 15:5152-5168. Medline

Cohen YE, Knudsen El (1996) Representation of frequency in the primary auditory field of the barn owl forebrain. J Neurophysiol 76:3682-3692. Medline

Cohen YE, Knudsen El (1998) Representation of binaural spatial cues in Field $L$ of the barn owl forebrain. J Neurophysiol 79:879-890. Medline

Cohen YE, Miller GL, Knudsen El (1998) Forebrain pathway for auditory space processing in the barn owl. J Neurophysiol 79:891902. Medline

Cynader M, Berman N (1972) Receptive-field organization of monkey superior colliculus. J Neurophysiol 35:187-201. Medline

Day ML, Delgutte B (2013) Decoding sound source location and separation using neural population activity patterns. J Neurosci 33:15837-15847. CrossRef Medline

De la Rocha J, Doiron B, Shea-Brown E, Josi K, Reyes A (2007) Correlation between neural spike trains increases with firing rate. Nature 448:802-806. CrossRef Medline

Derey K, Valente G, de Gelder B, Formisano E (2016) Opponent coding of sound location (azimuth) in planum temporale is robust to sound-level variations. Cereb Cortex 26:450-464. CrossRef Medline

Downer JD, Niwa M, Sutter ML (2015) Task engagement selectively modulates neural correlations in primary auditory cortex. J Neurosci 35:7565-7574. CrossRef Medline

Dykstra AR, Burchard D, Starzynski C, Riedel H, Rupp A, Gutschalk A (2016) Lateralization and binaural interaction of middle-latency and late-brainstem components of the auditory evoked response. $\mathrm{J}$ Assoc Res Otolaryngol 17:357-370. CrossRef Medline

Ecker AS, Berens P, Cotton RJ, Subramaniyan M, Denfield GH, Cadwell CR, Smirnakis SM, Bethge M, Tolias AS (2014) State dependence of noise correlations in macaque primary visual cortex. Neuron 82:235-248. CrossRef Medline

Ecker AS, Berens P, Tolias AS, Bethge M (2011) The effect of noise correlations in populations of diversely tuned neurons. J Neurosci 31:14272-14283. CrossRef Medline
Eisenman LM (1974) Neural encoding of sound location: an electrophysiological study in auditory cortex (Al) of the cat using free field stimuli. Brain Res 75:203-214. Medline

Fisher RA (1936) The use of multiple measurements in taxonomic problems. Ann Eugen 7:179-188. CrossRef

Gawne TJ, Richmond BJ (1993) How independent are the messages carried by adjacent inferior temporal cortical neurons? J Neurosci 13:2758-2771. Medline

Goodman DFM, Benichoux V, Brette R (2013) Decoding neural responses to temporal cues for sound localization. Elife 2:e01312. CrossRef

Gordon B (1973) Receptive fields in deep layers of cat superior colliculus. J Neurophysiol 36:157-178. Medline

Goris RLT, Movshon JA, Simoncelli EP (2014) Partitioning neuronal variability. Nat Neurosci 17:858-865. CrossRef Medline

Gray CM, Maldonado PE, Wilson M, McNaughton B (1995) Tetrodes markedly improve the reliability and yield of multiple single-unit isolation from multi-unit recordings in cat striate cortex. J Neurosci Methods 63:43-54. Medline

Grothe B, Pecka M, McAlpine D (2010) Mechanisms of sound localization in mammals. Physiol Rev 90:983-1012. CrossRef Medline

Grytskyy D, Tetzlaff T, Diesmann M, Helias M (2013) A unified view on weakly correlated recurrent networks. Front Comput Neurosci 7:131. CrossRef Medline

Herrero JL, Gieselmann MA, Sanayei M, Thiele A (2013) Attentioninduced variance and noise correlation reduction in macaque $\mathrm{V} 1$ is mediated by NMDA receptors. Neuron 78:729-739. CrossRef Medline

Imig TJ, Irons WA, Samson FR (1990) Single-unit selectivity to azimuthal direction and sound pressure level of noise bursts in cat high-frequency primary auditory cortex. J Neurophysiol 63:14481466. Medline

Jeanne JM, Sharpee TO, Gentner TQ (2013) Associative learning enhances population coding by inverting interneuronal correlation patterns. Neuron 78:352-363. CrossRef Medline

Jeffress LA (1948) A place theory of sound localization. J Comp Physiol Psychol 41:35-39. Medline

Karino G, George I, Loison L, Heyraud C, De Groof G, Hausberger M, Cousillas H (2016) Anesthesia and brain sensory processing: impact on neuronal responses in a female songbird. Sci Rep 6:39143. CrossRef

Knudsen El (1982) Auditory and visual maps of space in the optic tectum of the owl. J Neurosci 2:1177-1194.

Knudsen El (1984) Auditory properties of space-tuned units in owl's optic tectum. J Neurophysiol 52:709-723. Medline

Knudsen El, Blasdel GG, Konishi M (1979) Sound localization by the barn owl (Tyto alba) measured with the search coil technique. J Comp Physiol 133:1-11. CrossRef

Knudsen El, Cohen YE, Masino T (1995) Characterization of a forebrain gaze field in the archistriatum of the barn owl: microstimulation and anatomical connections. J Neurosci 15:5139-5151. Medline

Knudsen El, Knudsen PF (1983) Space-mapped auditory projections from the inferior colliculus to the optic tectum in the barn owl (Tyto alba). J Comp Neur 218:187-196. CrossRef Medline

Knudsen El, Knudsen PF, Masino T (1993) Parallel pathways mediating both sound localization and gaze control in the forebrain and midbrain of the barn owl. J Neurosci 13:2837-2852. Medline

Knudsen El, Konishi M (1978) Space and frequency are represented separately in auditory midbrain of the owl. J Neurophysiol 41:870884.

Kohn A, Coen-Cagli R, Kanitscheider I, Pouget A (2016) Correlations and neuronal population information. Annu Rev Neurosci 39:237256. CrossRef Medline

Kohn A, Smith MA (2005) Stimulus dependence of neuronal correlation in primary visual cortex of the macaque. J Neurosci 25: 3661-3673. CrossRef Medline

Konishi M (2003) Coding of auditory space. Annu Rev Neurosci 26:31-55. CrossRef Medline 
Konishi M (2012) How the owl tracks its prey. Am Sci 100:494. CrossRef

Köppl C (1997) Frequency tuning and spontaneous activity in the auditory nerve and cochlear nucleus magnocellularis of the barn owl Tyto alba. J Neurophysiol 77:364-377. Medline

Latham P, Roudi Y (2013) Role of correlations in population coding. In: Principles of neural coding, pp 121-138. Boca Raton: CRC Press.

Lee J, Groh JM (2014) Different stimuli, different spatial codes: a visual map and an auditory rate code for oculomotor space in the primate superior colliculus. PLoS One 9:e85017. CrossRef Medline

Liu S, Gu Y, DeAngelis GC, Angelaki DE (2013) Choice-related activity and correlated noise in subcortical vestibular neurons. Nat Neurosci 16:89-97. CrossRef Medline

Lyamzin DR, Macke JH, Lesica NA (2010) Modeling population spike trains with specified time-varying spike rates, trial-to-trial variability, and pairwise signal and noise correlations. Front Comput Neurosci 4:144. CrossRef Medline

McAlpine D, Jiang D, Palmer AR (2001) A neural code for lowfrequency sound localization in mammals. Nat Neurosci 4:396401. CrossRef Medline

McLaughlin SA, Higgins NC, Stecker GC (2016) Tuning to binaural cues in human auditory cortex. J Assoc Res Otolaryngol 17:37-53. CrossRef Medline

Middlebrooks JC, Knudsen El (1984) A neural code for auditory space in the cat's superior colliculus. J Neurosci 4:2621-2634. Medline

Middlebrooks JC, Pettigrew JD (1981) Functional classes of neurons in primary auditory cortex of the cat distinguished by sensitivity to sound location. J Neurosci 1:107-120. Medline

Miller JK, Ayzenshtat I, Carrillo-Reid L, Yuste R (2014) Visual stimuli recruit intrinsically generated cortical ensembles. Proc Natl Acad Sci USA 111:E4053-E4061. CrossRef

Miller LM, Recanzone GH (2009) Populations of auditory cortical neurons can accurately encode acoustic space across stimulus intensity. Proc Natl Acad Sci USA 106:5931-5935. CrossRef Medline

Moiseff A (1989) Bi-coordinate sound localization by the barn owl. J Comp Physiol A Neuroethol Sens Neural Behav Physiol 164:637644. Medline

Moiseff A, Konishi M (1981) Neuronal and behavioral sensitivity to binaural time differences in the owl. J Neurosci 1:40-48. Medline

Okun M, Steinmetz NA, Cossell L, lacaruso MF, Ko H, Barthó P, Moore T, Hofer SB, Mrsic-Flogel TD, Carandini M, Harris KD (2015) Diverse coupling of neurons to populations in sensory cortex. Nature 521:511-515. CrossRef Medline

Palmer AR, King AJ (1982) The representation of auditory space in the mammalian superior colliculus. Nature 299:248-249. Medline

Paradiso MA (1988) A theory for the use of visual orientation information which exploits the columnar structure of striate cortex. Biol Cybern 58:35-49. CrossRef

Payne RS (1971) Acoustic location of prey by barn owls (Tyto alba). J Exp Biol 54:535-573. Medline

Pérez ML, Peña JL (2006) Comparison of midbrain and thalamic space-specific neurons in barn owls. J Neurophysiol 95:783-790. CrossRef Medline

Pérez ML, Shanbhag SJ, Peña JL (2009) Auditory spatial tuning at the crossroads of the midbrain and forebrain. J Neurophysiol 102:1472-1482. CrossRef Medline

Poganiatz I, Nelken I, Wagner H (2001) Sound-localization experiments with barn owls in virtual space: influence of interaural time difference on head-turning behavior. $J$ Assoc Res Otolaryngol 2:1-21. Medline

Ponce-Alvarez A, Thiele A, Albright TD, Stoner GR, Deco G (2013) Stimulus-dependent variability and noise correlations in cortical MT neurons. Proc Natl Acad Sci USA 110:13162-13167. CrossRef Medline
Quiroga RQ, Reddy L, Koch C, Fried I (2007) Decoding visual inputs from multiple neurons in the human temporal lobe. J Neurophysiol 98:1997-2007. CrossRef Medline

Rajan R, Aitkin LM, Irvine DR (1990) Azimuthal sensitivity of neurons in primary auditory cortex of cats. II. Organization along frequencyband strips. J Neurophysiol 64:888-902. Medline

Razak KA (2011) Systematic representation of sound locations in the primary auditory cortex. J Neurosci 31:13848-13859. CrossRef Medline

Razak KA, Yarrow S, Brewton D (2015) Mechanisms of sound localization in two functionally distinct regions of the auditory cortex. $\mathrm{J}$ Neurosci 35:16105-16115. CrossRef Medline

Ribrault C, Sekimoto K, Triller A (2011) From the stochasticity of molecular processes to the variability of synaptic transmission. Nat Rev Neurosci 12:375-387. CrossRef Medline

Richardson BD, Hancock KE, Caspary DM (2013) Stimulus-specific adaptation in auditory thalamus of young and aged awake rats. J Neurophysiol 110:1892-1902. CrossRef

Sabri MM, Adibi M, Arabzadeh E (2016) Dynamics of population activity in rat sensory cortex: network correlations predict anatomical arrangement and information content. Front Neural Circuits 10:49. CrossRef Medline

Schnupp JWH, Carr CE (2009) On hearing with more than one ear: lessons from evolution. Nat Neurosci 12:692-697. CrossRef Medline

Schönbrodt FD, Perugini M (2013) At what sample size do correlations stabilize? J Res Pers 47:609-612. CrossRef

Schumacher JW, Schneider DM, Woolley SMN (2011) Anesthetic state modulates excitability but not spectral tuning or neural discrimination in single auditory midbrain neurons. J Neurophysiol 106:500-514. CrossRef Medline

Schwab BC, van Wezel RJA, van Gils SA (2017) Sparse pallidal connections shape synchrony in a network model of the basal ganglia. Eur J Neurosci 45:1000-1012.

Seriès P, Latham PE, Pouget A (2004) Tuning curve sharpening for orientation selectivity: coding efficiency and the impact of correlations. Nat Neurosci 7:1129-1135. CrossRef Medline

Seung HS, Sompolinsky H (1993) Simple models for reading neuronal population codes. Proc Natl Acad Sci USA 90:10749-10753. Medline

Shadlen MN, Newsome WT (1998) The variable discharge of cortical neurons: implications for connectivity, computation, and information coding. J Neurosci 18:3870-3896. Medline

Silver NC, Dunlap WP (1987) Averaging correlation coefficients: should Fisher's z transformation be used? J Appl Psychol 72:146148. CrossRef

Smith MA, Kohn A (2008) Spatial and temporal scales of neuronal correlation in primary visual cortex. J Neurosci 28:12591-12603. CrossRef Medline

Smith MA, Sommer MA (2013) Spatial and temporal scales of neuronal correlation in visual area V4. J Neurosci 33:5422-5432. CrossRef Medline

Sompolinsky H, Yoon H, Kang K, Shamir M (2001) Population coding in neuronal systems with correlated noise. Phys Rev E Stat Nonlin Soft Matter Phys 64:051904. CrossRef Medline

Steinberg LJ, Fischer BJ, Peña JL (2013) Binaural gain modulation of spectrotemporal tuning in the interaural level difference-coding pathway. J Neurosci 33:11089-11099. CrossRef Medline

Steinberg LJ, Peña JL (2011) Difference in response reliability predicted by spectrotemporal tuning in the cochlear nuclei of barn owls. J Neurosci 31:3234-3242. CrossRef Medline

Syka J, Radionova EA, Popelár J (1981) Discharge characteristics of neuronal pairs in the rabbit inferior colliculus. Exp Brain Res 44: 11-18. Medline

Takahashi TT (2010) How the owl tracks its prey-II. J Exp Biol 213:3399-3408. CrossRef Medline

Tetzlaff T, Helias M, Einevoll GT, Diesmann M (2012) Decorrelation of neural-network activity by inhibitory feedback. PLoS Comput Biol 8:e1002596. CrossRef Medline 
Tsodyks M, Kenet T, Grinvald A, Arieli A (1999) Linking spontaneous activity of single cortical neurons and the underlying functional architecture. Science 286:1943-1946. Medline

Van Bergeijk WA (1962) Variation on a theme of Békésy: a model of binaural interaction. J Acoust Soc Am 34:1431-1437. CrossRef

Vonderschen K, Wagner $\mathrm{H}$ (2009) Tuning to interaural time difference and frequency differs between the auditory arcopallium and the external nucleus of the inferior colliculus. J Neurophysiol 101: 2348-2361. CrossRef Medline

Vonderschen K, Wagner $\mathrm{H}$ (2012) Transformation from a pure time delay to a mixed time and phase delay representation in the auditory forebrain pathway. J Neurosci 32:5911-5923. CrossRef Medline

Van Kan PL, Scobey RP, Gabor AJ (1985) Response covariance in cat visual cortex. Exp Brain Res 60:559-563. Medline

Von Trapp G, Buran BN, Sen K, Semple MN, Sanes DH (2016) A decline in response variability improves neural signal detection during auditory task performance. J Neurosci 36:11097-11106. CrossRef Medline

Wagner H (1993) Sound-localization deficits induced by lesions in the barn owl's auditory space map. J Neurosci 13:371-386. Medline
Wagner H, Kettler L, Orlowski J, Tellers P (2013) Neuroethology of prey capture in the barn owl (Tyto alba L.). J Physiol Paris 107:5161. CrossRef Medline

Wang Y, Peña JL (2013) Direction selectivity mediated by adaptation in the owl's inferior colliculus. J Neurosci 33:19167-19175. CrossRef Medline

Wang Y, Shanbhag SJ, Fischer BJ, Peña JL (2012) Population-wide bias of surround suppression in auditory spatial receptive fields of the owl's midbrain. J Neurosci 32:10470-10478. CrossRef Medline

Wiechert MT, Judkewitz B, Riecke H, Friedrich RW (2010) Mechanisms of pattern decorrelation by recurrent neuronal circuits. Nat Neurosci 13:1003-1010. CrossRef Medline

Yaeger DB, Trussell LO (2016) Auditory Golgi cells are interconnected predominantly by electrical synapses. J Neurophysiol 116: 540-551. CrossRef Medline

Zohar O, Shackleton TM, Palmer AR, Shamir M (2013) The effect of correlated neuronal firing and neuronal heterogeneity on population coding accuracy in guinea pig inferior colliculus. PLoS One 8:e81660. CrossRef Medline

Zohary E, Shadlen MN, Newsome WT (1994) Correlated neuronal discharge rate and its implications for psychophysical performance. Nature 370:140-143. CrossRef Medline 